4.

Derecho procesal penal 



\title{
¿DERECHO DE LAS PERSONAS JURÍDICAS A NO AUTO-INCRIMINARSE?
}

[Do Legal Persons have the Right not to incriminate themselves?]

\author{
Héctor Hernández Basualto* \\ Universidad Diego Portales, Santiago de Chile
}

\begin{abstract}
RESUMEN
El artículo trata el punto de si las personas jurídicas imputadas por delito tienen derecho a no auto-incriminarse como lo tienen las personas naturales. El examen del estado permite verificar una tendencia mayoritaria hacia la negación de semejante derecho. Se estudia los alcances prácticos del posible reconocimiento de un derecho como el descrito, $y$ se concluye que éstos son muy acotados,
\end{abstract} ABSTRACT
This article analyses whether legal
persons accused of a crime have the right
not to incriminate themselves, as natural
persons do. A revision of the legal status
allows ascertaining a major trend to
denying such right. The practical scope
of possibly recognizing a right such as
the aforementioned is studied and it is
concluded that it is very limited, to the
point that even those who deny the ex-

RECIBIDO el 20 de noviembre y ACEPTADO el 30 de diciembre de 2014

* Doctor en Derecho; profesor titular de derecho penal de la Universidad Diego Portales. Dirección postal: Facultad de Derecho, Universidad Diego Portales, Av. República 112, Santiago, Chile. Correo electrónico: hector.hernandez@udp.cl. Este trabajo se inscribe en el Proyecto Fondecyt 1120977, "Desafíos de la responsabilidad penal de las personas jurídicas", ejecutado por el autor en la Universidad Diego Portales en calidad de investigador responsable. 
al punto que hasta quienes niegan la existencia del derecho podrían aprobarlos. Por último, luego de mostrar cómo esta lectura parece subyacer en regulaciones de países donde en general se admite la existencia del derecho, el trabajo toma posición sobre la situación en el derecho chileno.

Palabras clave

Responsabilidad penal de las personas jurídicas - Derecho a no autoincriminarse. istence of such right may approve them. Finally, after showing how this interpretation seem to be underlying regulations in countries where the existence of such right is generally admitted, this work focuses on Chilean Law.

\section{KEYWORDS}

Criminal liability of legal persons Right to not incriminate oneself.

\section{INTRODUCCIÓN}

Objeto de este trabajo es la pregunta sobre si las personas jurídicas imputadas por un delito de acuerdo con la Ley No 20.393, sobre responsabilidad penal de las personas jurídicas, gozan también del derecho a no auto-incriminarse de que gozan las personas naturales y con qué alcances.

En la primera parte (II) se expondrá el estado de la discusión comparada en los términos en que tradicionalmente ésta se ha formulado, como una cuestión binaria referida a si las personas jurídicas tienen derecho a no auto-incriminarse o no. Sin perjuicio de que esta primera parte arroje un resultado tendencialmente favorable a la respuesta negativa, resultado que aquí se comparte por las razones que se expondrán, en la segunda parte (III) se hará notar que la cuestión realmente importante no es ésta, sino la concerniente a los alcances concretos de un derecho semejante. Porque, como se verá, aunque se afirme que las personas jurídicas gozan de un derecho a no auto-incriminarse, y esto incluso con rango constitucional, el contenido estricto de este derecho, es decir, el único que se impone conceptualmente, es bastante más modesto que lo que a primera vista pudiera creerse, como parecen confirmarlo algunas regulaciones comparadas, al punto que hasta quienes no aceptan la existencia del derecho podrían estar de acuerdo, por otras razones, con sus consecuencias. Por último, en una tercera parte (IV), se tomará posición sobre el asunto en el ordenamiento jurídico chileno.

Por "derecho a no auto-incriminarse" se entenderá aquí, en términos generales y sin mayores diferenciaciones, el derecho de su titular a no ser obligado de ningún modo a colaborar activamente con la persecución penal en su contra. Comprende, en consecuencia, el "derecho a guardar silencio", el derecho a no ser compelido a manifestar o entregar objetos y, en general, 
el derecho a no ser compelido a realizar ninguna actividad que favorezca la investigación y el eventual castigo de hechos que se le imputan. Por lo mismo, distinciones frecuentes en ordenamientos extranjeros recibirán una atención sólo limitada, de modo que las referencias al derecho comparado deben entenderse con esa reserva.

\section{LA FORMULACIÓN BINARIA TRADICIONAL Y}

\section{EL ESTADO DE LA CUESTIÓN}

Tradicionalmente la cuestión se ha planteado en términos de si las personas jurídicas son titulares del derecho a no auto-incriminarse o no lo son. Y como en general se admite que, al menos en lo que respecta a las personas naturales, éste es un derecho con rango constitucional ${ }^{1}$, la discusión sobre su pertinencia respecto de las personas jurídicas suele plantearse también como una de carácter constitucional, en principio con importantes consecuencias para la amplitud del campo de maniobra disponible para el legislador democrático en la materia. A continuación se ofrece un breve panorama del estado de la cuestión en el plano del derecho internacional de los derechos humanos y del derecho constitucional comparado, que sugiere, en el primer caso, que se trata de una cuestión abierta y, en el segundo, que la tendencia dominante es hacia la respuesta negativa.

\section{Los tratados internacionales sobre derechos humanos vinculantes para} Chile.

El derecho a no auto-incriminarse está consagrado con efecto vinculante para Chile en el artículo 14.3 letra g) del Pacto internacional de derechos politicos y civiles (= PIDPC.) y en el artículo 8.2 letra g) de la Convención americana de derechos humanos (= CADH.), preceptos que, sin embargo, no aportan nada al objeto de este trabajo, en la medida en que está fuera de discusión que sólo las personas naturales y no las personas jurídicas son titulares de los derechos consagrados en dichos instrumentos inter-

${ }^{1}$ En el caso chileno, como se sabe, la Constitución de 1980 no consagra explícitamente el derecho a no auto-incriminarse, sino sólo el derecho a no ser obligado a declarar contra sí mismo bajo juramento (artículo 19 No 7 letra f CPol.). Sin perjuicio de que tal vez se pueda derivar un genuino derecho amplio de no autoincriminación de la fórmula genérica del artículo 19 No 3 inciso $6^{\circ} \mathrm{CPol}$., que obliga al legislador a establecer las garantías de un justo y racional procedimiento, lo cierto es que la vigencia de un tal derecho amplio sólo resulta indiscutible en virtud de los instrumentos internacionales en materia de derechos humanos vigentes en Chile, a los que se hará referencia luego. 
nacionales ${ }^{2}$. Por eso no hay jurisprudencia de los órganos internacionales competentes que pueda invocarse en Chile en favor de un supuesto derecho de las personas jurídicas a no auto-incriminarse.

\section{Jurisprudencia internacional no vinculante pero influyente.}

No obstante lo anterior, se podría querer invocar la autoridad de jurisprudencia internacional no vinculante para Chile, pero de prestigio $\mathrm{y}$ tradicionalmente influyente en nuestro medio, en concreto la jurisprudencia del Tribunal Europeo de Derechos Humanos y, en la medida en que también tematiza garantías de particulares que se ven afectadas por el derecho europeo, del Tribunal de Justicia de la Unión Europea.

El Convenio europeo de derechos humanos (= CEDH.) admite expresamente en su artículo 34 que, junto a cualquier "persona física" o "grupo de particulares", también cualquier "organización no gubernamental" pueda demandar a un Estado por una violación a los derechos consagrados en él y de la cual "se considere víctima", a lo que debe agregarse que el Tribunal Europeo de Derechos Humanos ha reconocido desde antiguo la titularidad de las personas jurídicas sobre ciertos derechos consagrados en el Convenio.

Pues bien, en lo que concierne específicamente a un posible derecho de las personas jurídicas a no auto-incriminarse, lo único que puede decirse en la actualidad de la jurisprudencia del Tribunal Europeo de Derechos Humanos es que por una parte se admite sin discusión que, a pesar de no estar expresamente mencionado ni en el Convenio ni en sus Protocolos, el derecho a no auto-incriminarse es una garantía judicial protegida por dicho instrumento, que debe entenderse implícita en la cláusula general sobre garantías judiciales del artículo 6 del mismo ${ }^{3}$, al tiempo que, por la otra, se entiende de modo igualmente pacífico que hay garantías judiciales

\footnotetext{
${ }^{2}$ Conforme al artículo 1,2 CADH. para los efectos de la convención "persona es todo ser humano", de donde se sigue que no lo son las personas jurídicas. Sobre esto Gros Espiell, Héctor, La Convención americana y la Convención europea de derechos humanos (Santiago, Editorial Jurídica de Chile, 1991), p. 72. En cuanto al PIDPC., que los beneficiarios de los derechos reconocidos en el pacto son los "individuos", quedando excluidas las personas jurídicas de ese concepto, ha sido confirmado mediante el No 9 de la Observación General No 31 [80] del Comité de Derechos Humanos de Naciones Unidas, de 29 de marzo de 2004; esto, sin perjuicio de que derechos individuales puedan ejercerse (y reclamarse) colectivamente y de que acciones contra personas jurídicas puedan implicar la afectación de derechos de personas naturales. Sobre eso Joseph, Sarah - CASTAN, Melissa, The International Covenant on Civil and Political Rights (3a edición, New York, Oxford University Press, 2013), pp. 74 ss.

${ }^{3} \mathrm{Al}$ respecto, por todos, TreChsel, Stefan, Human Rights in Criminal Proceedings (New York, Oxford University Press, 2005), pp. 340 ss.
} 
del artículo 6 del Convenio que pueden favorecer también a las personas jurídicas. Más allá de estos márgenes, lo concreto es que el Tribunal Europeo de Derechos Humanos nunca se ha pronunciado específicamente sobre el objeto de este trabajo, pues, en efecto, la ya abundante jurisprudencia sobre el derecho a no auto-incriminarse como garantía protegida por el Convenio ha versado exclusivamente sobre la situación de personas naturales ${ }^{4}$, en tanto que aquélla que ha aplicado garantías judiciales del artículo 6 a personas jurídicas ha versado exclusivamente sobre otras garantías, tales como el derecho a ser juzgado por un tribunal independiente e imparcial ${ }^{5}$, a una audiencia oral y pública ${ }^{6}$, a la igualdad de $\operatorname{armas}^{7} \mathrm{o}$ a ser juzgado en un tiempo razonable ${ }^{8}$, entre otros, pero no

${ }^{4}$ En "Funke v. Francia" (25 de febrero de 1993, solicitud 10828/84) y en "J.B. v. Suiza" (3 de mayo de 2001, solicitud 31827/96) se trataba de individuos en calidad de contribuyentes; en "Weh v. Austria" (8 de abril de 2004, solicitud 38544/97) y en "O'Halloran y Francis v. Reino Unido" (29 de junio de 2007, solicitudes $15809 / 02$ y 25624/02) de individuos en calidad de propietarios de automóviles involucrados en infracciones viales; en Serves v. Francia (20 de octubre de 1997, solicitud 82/1996/671/893, rechazada), “Allan v. Reino Unido” (5 de noviembre de 2002, solicitud 48539/99) y "Brusco v. Francia” (14 de diciembre de 2010, solicitud 1466/07), de sospechosos de asesinato; en "Jalloh v. Alemania" (11 de julio de 2006, solicitud 54810/00), de un sospechoso de tráfico de drogas; en "John Murray v. Reino Unido" (8 de febrero de 1996, solicitud 18731/91, rechazada) y "Heaney y McGuinness v. Irlanda" (21 de diciembre de 2000, solicitud 34720/97), de sospechosos de terrorismo; en "Shannon v. Reino Unido" (4 de octubre de 2005, solicitud 6563/03), de un sospechoso de contabilidad falsa y conspiración para defraudar; en tanto que en "Saunders v. Reino Unido" (17 de diciembre de 1996, solicitud 19187/91) y en su secuela I.J.L. y otros $v$. Reino Unido (19 de septiembre de 2000, solicitudes 29522/95, 30056/96 y 30574/96), de individuos imputados por manipulación del precio de acciones. Todos los fallos del Tribunal Europeo de Derechos Humanos citados en este trabajo están disponibles en distintos idiomas en el sitio: http://hudoc.echr.coe.int

5 "San Leonard Band Club v. Malta" (29 de julio de 2004, solicitud 77562/01); “Gazeta Ukraina-Tsentr v. Ucrania” (15 de julio de 2010, solicitud 16695/04).

6 "Coorplan-Jenni GmbH y Hascic v. Austria" (27 de julio de 2006, solicitud 10523/02).

7 "Dombo Beheer v. Holanda" (27 de octubre de 1993, solicitud 14448/88, erróneamente citado como reconocimiento de un derecho a no auto-incriminarse de las personas jurídicas por ENGELHART, Marc, Sanktionierung von Unternehmen und Compliance [Berlin, Duncker \& Humblot, 2010], p. 475 n. 151, en circunstancias que se trataba de todo lo contrario: de una empresa a la que no se le permitió presentar prueba a través de su representante); Dacia S.R.L. v. Moldavia (18 de marzo de 2008, solicitud 3052/04); "European University Press GmbH v. Austria" (24 de junio de 2010, solicitud 36942/05).

8 "Comingersoll S.A. v. Portugal" (6 de abril de 2000, solicitud 35382/97); 
sobre el derecho a no auto-incriminarse, sin que, por lo demás, el Tribunal Europeo de Derechos Humanos haya declarado alguna vez la pertinencia general o in totum del artículo 6 respecto de las personas jurídicas.

Por cierto puede verse en la asunción del principio "nemo tenetur" como garantía judicial protegida por el Convenio y en el simultáneo reconocimiento a las personas jurídicas de otras garantías judiciales que comparten el mismo domicilio un escenario tendencialmente favorable al reconocimiento específico de un derecho a no auto-incriminarse de dichas personas ${ }^{9}$, pero el dato inequívoco y que interesa destacar en este lugar es que el Tribunal Europeo de Derechos Humanos no se ha pronunciado sobre el punto específico. Y esto debe destacarse porque no son inusuales en la literatura presentaciones de la situación jurisprudencial en el sistema europeo de derechos humanos que parecen sugerir lo contrario ${ }^{10}$.

En lo que concierne ahora a la jurisprudencia del Tribunal de Justicia de la Unión Europea en procedimientos sancionatorios por infracciones a la libre competencia, el fallo en el caso "Orkem", de 1989, estableció los criterios que rigen hasta hoy los deberes de colaboración de las empresas contra las que se dirige el procedimiento ${ }^{11}$. Mediante este fallo se rechazó

"Marpa Zeeland B.V. y Metal Welding B.V. v. Holanda" (9 de noviembre de 2004, solicitud 46300/99).

${ }^{9}$ Como lo "más probable", aunque reconociendo que el Tribunal Europeo de Derechos Humanos no se había pronunciado todavía, lo ve van Kempen, Piet Hein, Human Rights and Criminal Justice Applied to Legal Persons, en Electronic Journal of Comparative Law 14 (2010) 3, p. 16. Disponible en: http://www.ejcl.org/143/ art143-20.pdf

${ }^{10}$ Cfr. Bajo Fernández, Miguel - Feijóo, Bernardo - Gómez-Jara, Carlos, Tratado de responsabilidad penal de las personas jurídicas (Madrid, Civitas, 2012), p. 291; SANGuiné, Odone, Derechos fundamentales de las personas jurídicas en el proceso penal, en Ontiveros, Miguel (coordinador), La responsabilidad penal de las personas juridicas (Valencia, Tirant lo Blanch, 2014), pp. 449 s.; Gimeno, Jordi, El proceso penal de las personas jurídicas (Cizur Menor, Aranzadi, 2014), p. 240. Excesivamente categórica resulta también la afirmación de TRECHSEL, Stefan, cit. (n. 3), p. 349 n. 33, haciendo suyo el razonamiento de la recurrente recogido por el Informe de la Comisión en el caso Société Sténuit con Francia (1992), que se limita a afirmar la procedencia de garantías judiciales respecto de las personas jurídicas, sin hacerse cargo del principio "nemo tenetur" (en la especie se trataba de una empresa que invocaba para sí una ley de amnistía penal), causa que concluyó con un acuerdo de las partes.

${ }^{11}$ Sentencia del Tribunal de Justicia de la Unión Europea, de 18 de octubre de 1989 (“Orkem/Comisión”, 374/87). El mismo criterio siguen, entre otras, las sentencias del Tribunal de Justicia de la Unión Europea de 7 de enero de 2004 (“Aalborg Portland y otros/Comisión”, C-204/00 P, C-205/00 P, C-211/00 P, C-213/00 P, C-217/00 P y C-219/00 P, apartados 61 y 65), de 14 de julio de 2005 (“ThyssenKrupp/Comisión”, C-65/02 P y C-73/02 P, apartado 49), de 25 de enero de 2007 (“Dalmine SpA/Comisión”, C-407/04 P, apartado 34) y de 24 de septiem- 
un derecho amplio a la no auto-incriminación, comprensivo de un derecho a guardar silencio o a no colaborar, y sólo se aceptó un derecho a negarse a confesar abiertamente, entendiéndose que las preguntas de la Comisión Europea deben tener como límite el derecho de defensa de la empresa (considerandos $32^{\circ}$ ss.), el que puede verse afectado si en concreto se obliga a ésta a reconocer participación en el hecho prohibido. Para estos efectos se desarrolló la distinción entre preguntas destinadas exclusivamente a esclarecer hechos, como, por ejemplo, el hecho de una reunión de productores, y preguntas cuya respuesta implica reconocimiento del hecho prohibido, como, por ejemplo, la pregunta por las medidas adoptadas en orden a establecer o mantener niveles de precios satisfactorios para todos los oferentes, que si bien sirve para una aclaración fáctica, lleva implícita la aceptación de una actividad ilícita (considerandos $35^{\circ}$ ss.).

Esta jurisprudencia ha sido objeto de fuerte crítica por parte de la literatura, fundamentalmente por algunas afirmaciones muy desafortunadas del fallo del caso "Orkem", las que, sin embargo, no parecen comprometer la plausibilidad de sus conclusiones. En la especie se trataba de una empresa química francesa a la que la Comisión Europea requirió la entrega de antecedentes preparatorios para una acusación por prácticas contrarias a la libre competencia. Atendido que las disposiciones comunitarias en cuestión no consideraban un derecho a guardar silencio, el tribunal se preguntó por la existencia de principios generales de los cuales pudiera emanar un derecho semejante. En primer lugar constató que en general los ordenamientos nacionales europeos reconocen un derecho a no autoincriminarse sólo a las personas naturales, no a las personas jurídicas (considerando 29). Fue en el tratamiento de los tratados internacionales en materia de derechos humanos, sin embargo, que su argumentación se volvió insostenible. Así, respecto del artículo $6 \mathrm{CEDH}$. constató que ni la letra de la disposición ni la jurisprudencia del tribunal de Estrasburgo reconocían un derecho a no auto-incriminarse (considerando 30), lo que indudablemente dejó de ser cierto con el ya mencionado fallo en el caso "Funke". Y en lo que concernía al artículo 14 PIDPC., en vez de limitarse a constatar que las personas jurídicas no se benefician de los derechos consagrados en el Pacto, como argumento de fondo señaló que el precepto tendría aplicación exclusivamente respecto de personas acusadas por un

bre de 2009 ("Erste Group Bank AG y otros/Comisión”, C-125/07 P, C-133/07 P, C-135/07 P y C-137/07 P, apartado 271). Véase también las sentencias del Tribunal de Primera Instancia de 8 de marzo de 1995 (“Société générale/Comisión”, T-34/93, apartados 72 ss.) y de 20 de febrero de 2001 ("Mannesmannröhren-Werke AG/Comisión”, T 112/98, apartados 63 a 67). Los fallos del Tribunal de Justicia de la Unión Europea están disponibles en diversos idiomas en el sitio: http://curia.europa.eu 
delito en un procedimiento ante un tribunal y no en el ámbito de una investigación de libre competencia (considerando 31), con lo cual sostuvo una interpretación del principio "nemo tenetur" muy por debajo de la comprensión dominante, expresada en la jurisprudencia del Tribunal Europeo de Derechos Humanos.

Se puede apreciar, sin embargo, que lo insostenible en lo expresado por el Tribunal de Justicia de la Unión Europea lo es ya incluso respecto de personas naturales, pues no es cierto que el Convenio europeo de derechos humanos no proteja de la auto-incriminación ni que ésta sólo se dé en el marco de procedimientos formalmente definidos como penales. Pero eso se puede corregir sin necesidad de reconocer también a las personas jurídicas ese derecho. En ausencia de pronunciamiento expreso del Tribunal Europeo de Derechos Humanos sigue en pie la fuerza expresiva de su constatación en cuanto a que los ordenamientos europeos no coinciden en el punto, de modo que el compromiso adoptado resulta a lo menos plausible ${ }^{12}$.

\section{La jurisprudencia constitucional comparada.}

Una muy sintética revisión de la jurisprudencia constitucional comparada muestra que no existe consenso universal al respecto, aunque se puede apreciar una cierta tendencia mayoritaria hacia la negación de un derecho a las personas jurídicas a la no auto-incriminación.

a) Estados Unidos de América. La Suprema Corte de los Estados Unidos de América ha negado a las personas jurídicas la protección contra la auto-incriminación que provee la Quinta Enmienda de la Constitución de ese país desde el más que centenario caso "Hale v. Henkel"13. En la especie se había requerido del representante de la sociedad contra la que se dirigía el procedimiento tanto su testimonio sobre hechos propios de la compañía como la entrega de documentos de la misma, a lo que éste se negó, entre otras razones, porque hacerlo podía incriminarlo tanto a él mismo como a la sociedad. Como en el mismo procedimiento se le había garantizado inmunidad personal, la cuestión a resolver era si la posible incriminación de la sociedad podía justificar su negativa, lo que fue rechazado por la Corte, dando así lugar a la "doctrina de la entidad colectiva" ("Collective Entity Doctrine", conocida también como "Entity Exception”).

En lo que llegaría a ser una constante de su jurisprudencia posterior sobre el particular, la Corte invocó en favor de su decisión las devastadoras

${ }^{12}$ Una valoración favorable del compromiso desde perspectiva anglosajona en Trainor, Scott A., A Comparative Analysis of a Corporation's Right Against Self-Incrimination, en Fordham Int'l Law Journal, 18 (1994-1995), pp. 2173 ss., 2185 s.

${ }^{13} 201$ U.S. 43 (1906). 
consecuencias prácticas que para la persecución penal de las personas jurídicas tendría que se les reconociera un derecho semejante. Y a la hora de fundarla conceptual y materialmente recurrió a dos ideas: por una parte, a la naturaleza esencialmente personalísima del privilegio, que hace que no sea susceptible de ejercicio a través de representantes ${ }^{14} ; \mathrm{y}$, por la otra, a la circunstancia de que, a diferencia de las personas naturales, que tienen una existencia independiente del Estado, la persona jurídica (en la especie: la sociedad) es una creación del Estado que recibe poderes que sólo se extienden hasta el punto fijado por el derecho que la crea, de donde se derivaría el derecho del Estado para investigar el ejercicio de esos poderes, contexto en el que puede legítimamente interrogar a la sociedad sobre cómo lo ha hecho y demandarle los documentos y objetos que dan cuenta de ello ${ }^{15}$.

Posteriormente la Corte aporta razones materiales adicionales para excluir del privilegio a las personas jurídicas en "United States v. White"16, donde, además de la insistencia en las razones ya mencionadas, se alude especialmente al "cruel dilema" en que se encuentra el individuo que debe elegir entre colaborar con su condena, mentir o incurrir en desacato ${ }^{17}$, di-

14 "El derecho de una persona a no incriminarse a sí misma bajo la Quinta Enmienda es un privilegio puramente personal del testigo. Nunca estuvo destinado a permitirle alegar el hecho de que una tercera persona pudiera ser incriminada por su testimonio, aunque fuera el agente de dicha persona... La pregunta de si una sociedad es una 'persona' en el sentido de esta enmienda realmente no se presenta, excepto tal vez cuando una sociedad es llamada a responder un pliego de posiciones, pues tratándose de evidencia oral sólo puede ser oída en la persona de alguno de sus agentes o empleados. La enmienda está limitada a una persona que en un caso criminal puede ser compelida a ser testigo contra sí misma, y si no puede invocar el privilegio de una tercera persona, ciertamente no puede invocar el privilegio de una sociedad', 201 U.S. 43, 69 s.

${ }^{15} 201$ U.S. 43, 74 s.

${ }^{16} 322$ U.S. 694 (1944).

${ }^{17}$ En White se lee lo siguiente: "El privilegio constitucional contra la auto-incriminación es esencialmente personal, aplicable sólo a personas naturales. Se desarrolla a partir de la alta opinión y consideración de nuestro sistema jurídico por juicios penales y procedimientos de investigación que se conduzcan en un plano de dignidad, humanidade imparcialidad. Está diseñado para prevenir el uso del proceso legal para sacar a la fuerza de los labios del individuo acusado la evidencia necesaria para condenarlo, o para forzarlo a producir y validar documentos personales o efectos que pudieran incriminarlo. De este modo se evita la tortura física y otros modos menos violentos pero igualmente reprobables de obligar a la producción de evidencia incriminatoria. Los persecutores están obligados a buscar evidencia independiente en lugar de descansar en prueba extraida por la fuerza de la ley a los individuos. Los males inmediatos y potenciales de la auto-revelación obligatoria van más allá de cualquier dificultad que el ejercicio del privilegio pueda imponer a la sociedad en la detección y persecución del crimen. Aunque el privilegio sea materia de 
lema que históricamente subyace al derecho contra la auto-incriminación ${ }^{18}$ y que, se entiende, no enfrenta un constructo jurídico como es la persona jurídica. La importancia de White respecto del objeto de este trabajo radica, además, en que extendió la excepción a otro tipo de personas jurídicas, en este caso a un sindicato, con el argumento de que el sindicato también tenía un carácter impersonal, que no encarnaba los intereses personales de sus afiliados, sino que básicamente sus intereses colectivos ${ }^{19}$. Esta idea que, aunque ampliaba, sugería todavía un criterio de restricción, se abandona luego en "Bellis v. United States"20, donde se resuelve que la excepción rige aunque la entidad encarne intereses personales, pues lo decisivo es que por su organización se le reconozca como una entidad independiente de sus miembros ${ }^{21}$.

Presentada la posición de la jurisprudencia constitucional estadounidense y las razones que la sustentan, conviene ahora distinguirla con toda claridad de otros desarrollos jurisprudenciales de la misma Corte sobre los alcances de la Quinta Enmienda, particularmente en materia de entrega de documentos, desarrollos que, aunque relacionados, en rigor versan sobre ciertos alcances del privilegio respecto de las perso nas naturales. La distinción se justifica porque dichos desarrollos se apartan en mayor o menor grado del desarrollo jurisprudencial en otras tradiciones constitucionales y en el plano del derecho internacional de los derechos humanos, con lo cual se corre el riesgo de que, en ausencia de una distinción adecuada, su crítica conlleve también una crítica a la negación de un derecho a no

abuso y uso indebido, está firmemente arraigado en nuestro marco constitucional y legal como un baluarte contra métodos inicuos de persecución", 322 U.S. 694, 698 s.

${ }^{18}$ Como se expresa paradigmáticamente, por ejemplo, en "Murphy v. Waterfront Commission", 378 U.S. 52 (1964), 55: "El privilegio contra la auto-incriminación... refleja muchos de nuestros valores fundamentales y más nobles aspiraciones: nuestra reluctancia a someter a quienes son sospechosos de crimen al cruel dilema entre auto-acusación, perjurio o desacato... nuestro temor a que las declaraciones auto-incriminatorias vayan a ser sonsacadas con tratos inhumanos y abusos... nuestro respeto a la inviolabilidad de la personalidad humana". La cita completa da cuenta de otros valores, tales como la preferencia por un proceso acusatorio, que, como bien destacan GOBERT, James - Punch, Maurice, Rethinking Corporate Crime (London, Butterworths, 2003), p. 197, son también pertinentes respecto de personas jurídicas, pero el énfasis en la condición humana es sin duda ostensible.

${ }^{19} 322$ U.S. 694, 701 ss.

20417 U.S. 85 (1974).

${ }^{21}$ En "Bellis" se trataba de un pequeño estudio de abogados, quedando sólo sin resolver si una pequeña empresa familiar o un emprendimiento conjunto transitorio podían recibir un tratamiento diferente, aunque incluso en reuniones muy pequeñas el factor organizativo puede incidir en que se dé la excepción de entidad. 
auto-incriminarse de las personas jurídicas que, al menos en esa medida, sería infundada.

El primer desarrollo, considerado por la literatura una simple dimensión específica de la doctrina de la entidad colectiva, consiste en haberle negado al agente de la persona jurídica el derecho a oponerse a entregar documentos de la empresa incluso cuando esa entrega pudiera resultar incriminatoria para él mismo, a título personal. Desde "Wilson v. United States"22 se mantiene que la protección constitucional contra la auto-incriminación mediante la entrega compulsiva de documentos dice relación con los documentos privados del individuo, pero no con los documentos corporativos, propios de la persona jurídica, con independencia de que en su composición haya intervenido el agente y sin que la sola tenencia o custodia de los mismos pueda considerarse fuente suficiente de un derecho a su respecto ${ }^{23}$. A esto debe agregarse la llamada "excepción de registros obligatorios" ("Required Records Exception"), conforme a la cual deben entregarse aquellos registros que son obligatorios para las empresas en determinados contextos regulatorios, excepción que fue preparada por la invocación recurrente de las facultades de inspección del Estado sobre entidades que existen sólo gracias a su voluntad, y definitivamente sentada en "Shapiro v. United States"24, cuya importancia radica en que incluso deben entregarse documentos privados que se tienen en la empresa cuando su conservación es obligatoria en un contexto regulatorio determinado ${ }^{25}$.

El segundo desarrollo, mucho más general y conocido, consiste en reservar la protección constitucional, sobre la base del tenor literal de la Quinta Enmienda, para el testimonio propiamente tal o, en todo caso, para conductas con un sentido comunicativo equivalente. Esta tesis, desarrollada principalmente a partir de "Schmerber v. California" 26 , fue ratificada para el ámbito específico de la entrega de documentos por "Fisher

2221 U.S. 361 (1911).

${ }^{23} 221$ U.S. 361,377 ss.

${ }^{24} 335$ U.S. 1 (1948).

${ }^{25}$ Mayor precisión se alcanza mediante "Marchetti" (390 U.S. 39 [1968]) y "Grosso" (390 U.S. 62 [1968]), que enuncian los tres requisitos de la doctrina de los registros obligatorios: primero, que los propósitos del requerimiento estatal sean esencialmente regulatorios, es decir, no orientados al descubrimiento de delitos; segundo, que la documentación requerida sea de un tipo que usualmente los agentes regulados deban mantener; $y$, tercero, que los documentos tengan un "aspecto público" que los asemeje a documentos públicos [sobre esto LAFAVE, Wayne R. - IsraEL, Jerold H. - KIng, Nancy J., Criminal Procedure (4a edición, St. Paul, West, 2004), p. 469].

${ }^{26} 384$ U.S. 757 (1966), referido a una extracción de sangre sin la voluntad del imputado; la tesis continúa con "United States v. Wade" (388 U.S. 218 [1967]), 
v. United States"27, conforme al cual la entrega del documento, su "producción" en el lenguaje de la Corte, sólo goza de protección constitucional si en cuanto tal tiene un carácter comunicativo e incriminador ("doctrina del acto de producción", "Act-of-Production Doctrine") ${ }^{28}$.

La extensión de la doctrina del acto de producción planteó la cuestión sobre la vigencia de la doctrina de la entidad colectiva en lo que concierne al deber de los agentes de entregar la documentación corporativa cuando la entrega pudiera ser incriminatoria para ellos mismos. El punto fue si las limitaciones implícitas en la nueva doctrina (entrega con significado comunicativo como acto de auto-incriminación en el sentido de la Enmienda) podían favorecer a quien actuara por una persona jurídica ${ }^{29}$, lo que vino a ser resuelto, en favor de la doctrina de la entidad colectiva, por "Braswell v. United States" ${ }^{\prime 30}$. Se trataba del único accionista de dos sociedades que objetó el requerimiento de documentación en su calidad de agente haciendo presente (en la lógica de la doctrina del acto de producción), que la entrega podía incriminarlo a él personalmente. La Corte hizo valer, sin embargo, que no se tiene derecho a la no auto-incriminación respecto de documentos que se tienen en representación de la sociedad, pues en este caso el acto de producción no es un acto del agente, sino de la sociedad ${ }^{31}$.

referido a muestras de voz y con "Gilbert v. California” (388 U.S. 263 [1967]), referido a muestras de letra manuscrita.

${ }^{27} 425$ U.S. 391 (1976).

${ }^{28}$ Según Fisher, la entrega de documentos puede tener carácter testimonial como reconocimiento de existencia, reconocimiento de posesión o control y como autentificación implícita o potencial, y desde esa perspectiva, según las circunstancias del caso, puede venir a colación la protección de la Quinta Enmienda (425 U.S. 391, 410 ss.).

${ }^{29}$ Sobre la dispersión de opiniones en las cortes inferiores después de estos fallos, véase Sweeney, Timothy F., The Fifth Amendment and Collective Entities, en Ohio St. Law Journal, 48 (1987), pp. 295 ss.; y Rothman, Mitchell L., Life after Doe, en U. Cin. Law Review, 56 (1987-1988), pp. 387 ss.

${ }^{30} 487$ U.S. 99 (1988). Sobre esto, Massing, Gregory, The Fifth Amendment, the Attorney-Client Privilege, and the Prosecution of White-Collar Crime, en Va. Law Review, 75 (1989), pp. 1179 ss.

${ }^{31}$ Con todo "Braswell" no ha dejado de tener consecuencias para la extensión de esta dimensión específica de la doctrina de la entidad colectiva, pues la Corte reconoció que entender el acto como uno propio de la entidad debía tener como consecuencia que no se pudiera usar en contra del agente el hecho de que fuera a través de una conducta suya que tuvo lugar ese acto de la entidad, al mismo tiempo que, sin embargo, pretendió que esto no implicara que no se pudiera usar el acto de producción de la entidad como evidencia contra el agente. La Corte procura compatibilizar ambos propósitos señalando que al jurado se le puede informar legítimamente que la entidad entregó la documentación (que la poseía, que es auténtica, 
Como se puede ver, la jurisprudencia estadounidense ha recortado significativamente los alcances del derecho de las personas naturales a la no auto-incriminación, de un modo que, aunque eventualmente plausible en alguno de sus extremos, no parece compatible con la jurisprudencia internacional en materia de derechos humanos, ni con la jurisprudencia constitucional de muchos Estados ni con nítidas decisiones de muchas legislaciones, entre ellas la chilena. Empero, esto no le resta ni una pizca de fuerza persuasiva a las razones tenidas en cuenta por dicha jurisprudencia para la negación de un derecho de las personas jurídicas a la no auto-incriminación, que es lo que importa en este trabajo.

b) Inglaterra. En la literatura se suele mencionar como extremo opuesto la situación en Inglaterra, donde se afirmó el derecho de las personas jurídicas a la no auto-incriminación mediante el fallo "Triplex Safety Glass Co. v. Lancegaye Safety Glass Ltd" (1934), de la High Court (King's Bench Division), del año 1939. En la especie se trataba de una empresa fabricante de lentes de seguridad (Triplex) que demandó a una empresa de la competencia (Lancegaye) y a su gerente por difamación, por la difusión de una circular con informaciones supuestamente desdorosas para la primera. En ese contexto la demandante solicitó que ambos demandados fuesen obligados a declarar al tenor de un cuestionario, a lo que ambos se negaron argumentando que hacerlo podía incriminarlos. Luego de una larga argumentación para fundar la justicia de la posición del representante en el caso concreto (en particular, la realidad del riesgo de incriminación), el tribunal resolvió escuetamente que lo mismo debía regir para la persona jurídica, pues no existirían razones para un tratamiento diferente, ya que si bien la persona jurídica no podía sufrir con la pena los mismos padecimiento que una persona natural, sí podía ser hecha

etc.), de modo que sea el jurado el que, atendida la posición del agente en la empresa, puede inferir que éste estaba en posesión de la misma y conocía su contenido, quedando abierta la posibilidad, en todo caso, de que el individuo pueda hacer valer que en el caso concreto el acto de producción en cuanto tal lo incrimina inevitablemente, por ejemplo, si es el único empleado de la sociedad. Hay voto disidente que ve en este ensayo la elusión de la Enmienda y sostiene que la única manera de poner orden sería garantizando inmunidad al agente. Es interesante, por último, tener presente que muchas veces estos requerimientos van asociados a una garantía de inmunidad cuando los requeridos hacen valer su derecho a no auto-incriminarse cuando esto es pertinente, aunque no inmunidad absoluta, sino sólo inmunidad en lo que concierne a lo probado directa o derivadamente gracias a la información entregada ("use or derivative use"- "inmunity"). El otorgamiento de inmunidad tuvo un importante espaldarazo con "United States v. Hubbell” (530 U.S. 27 [2000]). Sobre el conjunto véase Saltzburg, Stephen A. - CAPra, Daniel J., American Criminal Procedure Investigative (9a edición, St. Paul, West, 2010), pp. 635 s. 
penalmente responsable y verse por ello sujeta a graves consecuencias, de modo que no podía negársele una garantía que el derecho inglés reconoce hasta a la menos meritoria de las personas naturales ${ }^{32}$. Este punto de vista se ha mantenido en fallos posteriores ${ }^{33}$.

Ahora bien, al margen de que, en rigor, "Triplex" no da razones positivas en favor de la extensión del privilegio, lo que interesa destacar aquí es que esta jurisprudencia no impone límites al Parlamento inglés. El privilegio de no auto-incriminación, aun respecto de personas naturales, es un principio de "common law" que reconocidamente puede ser modificado y hasta suprimido por el Parlamento, como de hecho ha ocurrido en una serie de ámbitos específicos ${ }^{34}$, contra lo cual no sirven invocaciones constitucionales, toda vez que el poder constituyente radica en el propio Parlamento. Posibles restricciones sólo pueden provenir del sistema eu-

${ }^{32}$ [1939] 2 K.B. 395, 408 s. El tribunal expresamente hace propia la doctrina sentada por la Corte Suprema de Alberta (Canadá) al fallar el caso "Webster v. Solloway, Mills \& Co.”, [1930] 3 W.W.R. 445, 448, conforme a la cual sólo el legislador puede hacer excepciones a este principio de "common law".

${ }^{33}$ Véase, por ejemplo, el importante fallo "Rio Tinto Zinc Corporation and others v. Westinghouse Electric Corporation” ([1978] AC 547), donde se afirma la titularidad de las compañías sobre el privilegio contra la auto-incriminación conforme a Sección 14 de la Civil Evidence Act de 1968, en que se confronta con la jurisprudencia estadounidense. Es cierto que ha habido voces críticas en la propia jurisprudencia, pero hasta donde se puede ver, no han alcanzado a modificar la situación. Así, por ejemplo, en “British Steel v. Granada Television” ([1981] AC 1096), conocido por la House of Lords, donde se discutía sobre el deber de un medio televisivo de revelar la fuente de la que había obtenido documentos confidenciales de la demandante, asunto que fue resuelto afirmativamente sobre otras bases, al menos uno de los jueces refutó la alegación del derecho a no auto-incriminarse señalando que éste no era aplicable a personas jurídicas, ya que una corporación "no tiene cuerpo para ser pateado ni alma para ser condenada. El interés público consiste mucho más en hacer que las corporaciones revelen sus fechorías que en darles este escudo de privilegio", voto de Lord Denning [1981] AC 1096, 1127.

${ }^{34}$ Una detallada revisión de las numerosas restricciones o abrogaciones legislativas del privilegio puede verse en el voto de Lord Templeman en "AT \& T Istel Ltd. v. Tully" ([1992] 3 All ER 523, 530 ss.), donde incluso algunos jueces abogan por una restricción general más allá de dichas intervenciones del Parlamento. Por otra parte, existe una tendencia general de relajación del privilegio luego de que la Criminal Justice and Public Order Act de 1994 permitiera extraer del silencio del imputado conclusiones en su contra (secciones 34 y siguientes), pues aunque con esto no se deroga formalmente el privilegio (de ahí que el Tribunal Europeo de Derechos Humanos lo declarara compatible con el Convenio Europeo en "John Murray v. United Kingdom”, de 8 de febrero de 1996), evidentemente le resta importancia. Al respecto Gobert, James - Punch, Maurice, cit. (n. 18), p. 196. 
ropeo de derechos humanos ${ }^{35}$, contexto en el cual, sin embargo y como se ha demostrado, el punto específico de la vigencia del derecho respecto de las personas jurídicas no ha sido resuelto.

c) Canadá. Aun cuando en cuestiones de detalle el asunto podría considerarse todavía abierto, en general es claro que la tendencia del derecho canadiense es a no reconocer a las personas jurídicas un derecho a no auto-incriminarse. Si bien distintas jurisdicciones provinciales mantuvieron soluciones divergentes por algún tiempo ${ }^{36}$, mediante la sentencia en el caso "R. v. NM Paterson and Sons Ltd.", de 1980, la Suprema Corte de Canadá resolvió que el privilegio no era aplicable a las corporaciones, al menos en procedimientos por delitos que no requieren mens $\mathrm{rea}^{37}$. Posteriormente, la misma Corte, en "R. c. Amway Corp.", del año 1989, sostuvo en un discutible obiter dictum que en realidad el asunto había quedado completamente zanjado por "Paterson" ${ }^{38}$, junto con afirmar que las reglas tradicionales de "common law" contra la auto-incriminación en Canadá habían sido superadas por la legislación ${ }^{39}$.

Por último, con "Amway" habría quedado completamente zanjado que las personas jurídicas no serían titulares del derecho a no auto-incriminarse consagrado en la Sección 11 letra c) de la Carta canadiense de derechos $y$ libertades de 1982, con lo cual se resuelve negativamente la pregunta por el posible rango constitucional del asunto. La Corte resolvió de este modo tanto por la letra de la disposición, que impide que alguien pueda ser obligado a ser "testigo" contra sí mismo, en circunstancias en que en los casos en cuestión el único testigo es el representante, no la persona jurídica; pero, además, por su claro propósito de preservar la dignidad y

${ }^{35}$ Para lo cual, al margen de la posible responsabilidad internacional del Reino Unido como parte del Convenio Europeo, deben considerarse los mecanismos previstos en la Human Rights Act de 1998.

${ }^{36}$ Sobre esto, con detalle: WYLIE, Michael, Corporations and the Non-compellability Right in Criminal Proceedings, en Crim. Law Quaterly 33 (1990-1991), pp. 345 ss. Véase también, escuetamente: Theophilopoulos, Constantine, The Corporation and the Privilege against Self-Incrimination, en S. Afr. Mercantile Law Journal, 16 (2004), pp. 22 ss.

${ }^{37}$ En la especie se hacía valer que, conforme a la doctrina de la identificación, obligar a declarar al sujeto que era la "mente y voluntad directiva" ("directing mind and will") de la corporación equivalía a obligarla a declarar a ella misma. En vez de refutar el argumento, la Corte se limitó a declarar que la construcción sólo operaba cuando el delito requería mens rea o la corporación alegaba haber obrado con diligencia debida (porque la verificación de exigencias de ese tipo sólo sería posible en la conducta del órgano directivo, previa identificación de éste con la corporación), pero no en los demás casos, [1980] 2 R.C.S. 679, 680, 690 s.

${ }^{38}$ [1989] 1 S.C.R. 21, $31 \mathrm{s.}$

${ }^{39}$ [1989] 1 S.C.R. 21, 35 s. 
la intimidad de la persona, lo que a juicio de la Corte carece de sentido tratándose de entidades jurídicas ${ }^{40}$.

d) Australia. En Australia el asunto se resolvió en contra de la extensión del derecho a las personas jurídicas mediante la sentencia recaída en el caso "Environment Protection Authority v. Caltex Refining Co Pty Ltd", del año $1993^{41}$. En la especie se trataba de una empresa (Caltex) acusada de verter residuos industriales en el mar con infracción de las condiciones previstas para ello y que impugnó, alegando el privilegio de no auto-incriminación, la validez de las disposiciones legales en virtud de las cuales la autoridad administrativa le requirió documentación sobre sus vertidos. En lo que aquí interesa, luego de una muy completa revisión de la situación jurisprudencial en el ámbito del "common law", la mayoría de la High Court se hace cargo de la justificación tanto histórica como actual del privilegio, concluyendo que éste se basa en la protección de la libertad, la intimidad y la dignidad, de modo que sólo tiene sentido respecto de las personas naturales. Adicionalmente, destaca que si bien el privilegio existe también para mantener un justo equilibrio entre el Estado y el individuo imputado, esa función no sería necesaria tratándose de corporaciones, que por sus recursos cuentan con una posición mucho más fuerte que la que exhiben las personas naturales, reflexión que enlaza con la complejidad de las investigaciones criminales en que hay corporaciones comprometidas ${ }^{42}$.

Debe destacarse, por último, que en la especie sólo se discutía la procedencia de obligar a la persona jurídica a entregar documentación a través de sus empleados, porque la obligación de éstos de declarar como testigos contra la persona jurídica era ya una cuestión zanjada, al punto que se usa como argumento de sentido común, pues "no hace en absoluto sentido poner el privilegio a disposición de la corporación respecto de estos libros

${ }^{40}$ [1989] 1 S.C.R. 21, 37 ss., 42.

${ }^{41}$ Sobre "Caltex" pueden verse: STONE, Adrienne, Environment Protection Authority v. Caltex Refining Co Pty Ltd. Corporations and the Privilege against Self-Incrimination, en U.N.S.W. Law Review, 17 (1994), pp. 628 ss.; Hill, Jennifer, Corporate Rights and Accountability. The Privilege against Self-Incrimination and the Implications of Environment Protection Authority v. Caltex Refining Co Pty Ltd, en Corp. \& Bus. Law Review, 7 (1994), pp. 127 ss.; Garland, Norman, The Unavailability to Corporations of the Privilege against Self-Incrimination: A Comparative Examination, en N.Y.L. Sch. J. Int'l \& Comp. L., 16 (1996), pp. 55 ss. Para la situación previa a "Caltex", Ramsay, Ross, Corporations and the Privilege against Self-Incrimination, en U.N.S.W. Law Journal, 15 (1992), pp. 297 ss.

${ }^{42}$ [1993] HCA 74. El resumen en el texto se hace básicamente sobre la base del voto conjunto de los jueces Mason y Toohey, muy similar al del juez McHugh, pero bastante diferente al del juez Brennan, de modo que se mencionan argumentos o conclusiones que no hizo suyos este último. 
$y$ documentos cuando los oficiales de la corporación están obligados a declarar contra la corporación, a menos que ellos estén en condiciones de reclamar personalmente el privilegio" 33 .

El criterio sentado por "Caltex" fue recogido legislativamente en la Sección 187 de la Evidence Act de 1995, que dispone la "abolición" del privilegio contra la auto-incriminación para corporaciones ("bodies corporate" $)^{44}$.

e) Alemania. En el ámbito del derecho europeo-continental es relevante la posición adoptada por el Tribunal Constitucional Federal alemán, que a través de su fallo BVerfGE 95, 220 de 1997 sostuvo que el derecho a no auto-incriminarse favorecía exclusivamente a las personas naturales ${ }^{45}$. En la especie se trataba de una radioemisora privada a través de la cual se había convocado a una manifestación no autorizada de grupos kurdos. Sobre la base del deber legal de las radioemisoras de registrar sus emisiones, conservar los registros por un cierto tiempo y ponerlos a disposición de la autoridad, el organismo competente para la fiscalización de la radiodifusión privada requirió a la estación la entrega de los

${ }^{43}$ Apartado 48 del voto de Mason y Toohey, con referencia a "Smorgon v. Australia and New Zealand Banking Group Ltd.", [1976] HCA 53, y a "Penn-Texas Corporation v. Murat Anstalt" (1964) 1 QB 40.

${ }^{44}$ Del siguiente tenor: "187. Abolition of the privilege against self-incrimination for bodies corporate. (1) This section applies if, under a law of the Commonwealth or the Australian Capital Territory or in a proceeding in a federal court or an ACT court, a body corporate is required to: (a) answer a question or give information; or (b) produce a document or any other thing; or (c) do any other act whatever. (2) The body corporate is not entitled to refuse or fail to comply with the requirement on the ground that answering the question, giving the information, producing the document or other thing or doing that other act, as the case may be, might tend to incriminate the body or make the body liable to a penalty".

${ }^{45}$ En la literatura se suele citar como pronunciamiento previo favorable al reconocimiento del derecho a las personas jurídicas el acuerdo desestimatorio de 26 de febrero de 1975 (BVerfG. BB 1975, 1315), referido al ex miembro del directorio de una sociedad anónima a quien en un procedimiento por contravención contra la libre competencia seguido contra dicha sociedad se le negó el derecho a no declarar en razón de su antiguo cargo, acuerdo en el que, sin embargo, el tribunal se limitó a constatar que la legislación ordinaria sobre contravenciones efectivamente preveía este derecho para las personas jurídicas (a través del $\$ 444$ StPO.), las que lo ejercían a través de sus representantes (cual ya no era el caso del recurrente), pero sin pronunciarse sobre el status constitucional del mismo. Y más bien sugirió una opinión contraria, porque luego de descartar un peligro de auto-incriminación personal del recurrente (constaba que no había cometido delito y sus posibles contravenciones estaban prescritas) declaró que con eso decaerían en la especie las bases constitucionales para una posible limitación del deber de declarar como testigo, que en su concepto eran la dignidad humana y la libertad general de acción. 
registros de los programas en que se habría convocado a la manifestación. Ante la negativa de la estación, se le apercibió con apremios y se trabó una contienda administrativa, contexto en el cual la estación solicitó un pronunciamiento del Tribunal Constitucional Federal, alegando, entre otras supuestas vulneraciones constitucionales, la vulneración del derecho a no auto-incriminarse, que se entiende forma parte del derecho general de personalidad que se extrae a partir del artículo 2, I con el artículo 1, I de la Ley Fundamental o Grundgesetz (GG.) alemana ${ }^{46}$.

Para resolver, el tribunal recuerda primero la íntima relación existente entre el fundamento del derecho a no auto-incriminarse y la protección de la dignidad humana, para luego hacerse cargo de lo dispuesto en el artículo 19 III GG., que dispone que los derechos fundamentales rigen también para personas jurídicas nacionales, en la medida en que dichos derechos resulten aplicables a ellas "de acuerdo con su esencia". Y al respecto declara enfáticamente que el citado artículo excluye al menos la aplicación del derecho a no auto-incriminarse, porque ahí donde el derecho fundamental se conecta con cualidades, formas de expresión o relaciones que son propias y exclusivas de las personas naturales no sería posible su extensión a constructos jurídicos como son las personas jurídicas, máxime si la protección se establece en interés de la dignidad humana, que sólo las personas naturales pueden reclamar ${ }^{47}$.

Cabe decir, sin embargo, que el fallo introduce cierta dosis de ambigüedad cuando agrega que en los casos en que está comprometida la responsabilidad de la persona jurídica actúan por ella sus órganos, de modo que sólo éstos y no ella son autores, de modo que contra ella no se dirige ningún reproche de culpabilidad ni desaprobación ética, sino sólo una pretensión de compensación de los beneficios obtenidos del hecho ${ }^{48}$, lo

${ }^{46}$ Este derecho general de personalidad complementa, en la forma de un derecho innominado de libertad, los derechos específicos de libertad que protegen diversos aspectos de la personalidad. Su función consiste precisamente en asegurar, en el sentido del principio de la dignidad humana, las condiciones fundamentales del desarrollo de la personalidad no captadas por otros derechos. El derecho a no autoincriminarse forma parte de dicho derecho general de personalidad, pues el Estado no debe poner al individuo en una situación de conflicto en la que deba acusarse él mismo de delitos u otros hechos indebidos o pueda caer en la tentación de cometer un nuevo delito a través de declaraciones falsas o de ser sometido a apremios en caso de guardar silencio. Véase al respecto BVerfGE. 54, 148 (153); 79, 256 (268); 38, 105 (114 s.) y 56, 37 (41 s.).

${ }^{47}$ BVerfGE. 95, 220 (242), con referencia a BVerfGE. 56, 37 (42, 49). El tribunal declara expresamente que a las personas jurídicas no se les presenta el dilema propio de la auto-incriminación.

${ }^{48}$ BVerfGE. 95, 220 (242). 
que dejaría de ser cierto si el derecho alemán avanzara hacia una genuina responsabilidad penal de las personas jurídicas ${ }^{49}$. De ahí que no se pueda estar seguro de cuál sería la opinión del tribunal ante un posible cambio legislativo que introdujera una responsabilidad de esa naturaleza.

f) Otros ordenamientos. Por último, favorecerían el reconocimiento de un derecho a no auto-incriminarse de la persona jurídica, básicamente sobre la base, ya vista en la jurisprudencia inglesa, de no apreciar razones para una distinción entre personas naturales y jurídicas en la materia, la jurisprudencia neozelandesa, si bien sólo en base al "common law", con las mismas restricciones mencionadas para el caso inglés ${ }^{50}$, y la jurisprudencia noruega, esta última, en cambio, interpretando los alcances del Convenio europeo de derechos humanos sobre el particular ${ }^{51}$.

\section{Confirmación de la tendencia en la jurisprudencia constitucional chilena.}

Recientemente, en el único caso en que le ha correspondido pronunciarse al respecto (el llamado caso "Pollos")52, el Tribunal Constitucional chileno por unanimidad le ha negado a las personas jurídicas la titularidad sobre el derecho a no auto-incriminarse. En la especie se trataba del repre-

${ }^{49}$ Así lo entiende explícitamente, por ejemplo, la justificación del $₫ 18$ I (sobre derechos del imputado) del Proyecto de ley sobre Introducción de responsabilidad penal de empresas y otras asociaciones, presentado por el Estado de Rheinland-Westfalen al Bundesrat en 2014 (p. 74 s.). En rigor, la regla sólo dispone que "también" tienen derecho a ser interrogados como imputados los sospechosos de haber incurrido en el delito relevante para la ley, pero la fundamentación oficial entiende que lo mismo rige para los representantes de la persona jurídica en virtud de la remisión general del $\$ 13$ I a la Ordenanza Procesal Penal (cuyo $\$ 444$ contiene esa solución tratándose de procedimiento contravencional contra personas jurídicas), de modo que la regla del $\$ 18$ I constituiría sólo una ampliación (p. 75 s.). El proyecto se encuentra disponible en: https:/www.justiz.nrw.de/JM/justizpolitik/jumiko/beschluesse/2013/herbstkonferenz13/zw3/TOP_II_5_Gesetzentwurf.pdf. Sobre la discusión que ha provocado puede verse Schünemann, Bernd, Die aktuelle Forderung eines Verbandsstrafrechts. Ein kriminalpolitischer Zombie, en ZIS. (2014), pp. 1 ss.; Hoven, Elisa, Der nordrhein-westfälische Entwurfeines Verbandsstrafgesetzbuchs. Eine kritische Betrachtung von Begründungsmodell und Voraussetzungen der Straftatbestände, en ZIS. (2014), pp. 19 ss.

${ }^{50}$ Mediante el fallo de la Court of Appeal, en el caso "New Zealand Apple and Pear Marketing Board v. Master and Sons Ltd." (1986) 1 NZLR 191 (196).

${ }^{51}$ Mediante el fallo de la Corte Suprema de 1 de junio de 2011, HR-201101118-A, caso N N $^{\circ} 2011 / 456$, considerandos 26 ss. Si bien la Corte reconoce reiteradamente que el Tribunal Europeo de Derechos Humanos no se ha pronunciado sobre el particular, entiende que el punto de partida general es el igual trato entre personas naturales y jurídicas.

${ }^{52}$ Sentencia del Tribunal Constitucional, de 20 de agosto de 2013, rol No 238112. 
sentante legal de una sociedad avícola investigada por la Fiscalía Nacional Económica por supuestas conductas contrarias a la libre competencia, que fue citado en su calidad de representante legal a absolver posiciones bajo juramento sobre hechos atingentes a la investigación ${ }^{53}$. En ese contexto la sociedad solicitó la declaración de inaplicabilidad por inconstitucionalidad de las normas que permitían la imposición del deber de declarar bajo juramento, alegando que los mencionados preceptos vulnerarían la garantía del artículo 19 No 7 , letra f) CPol. ${ }^{54}$.

Al respecto el Tribunal Constitucional declaró que era notorio que la Constitución quiso restringir la aplicación del derecho a no ser obligado a declarar bajo juramento al procedimiento penal, razón por la cual lo habría explicitado en el No 7 , relativo específicamente a la libertad personal y a la seguridad individual, y no en el No 3 del artículo 19, donde se reúnen las garantías para todo procedimiento (considerando $10^{\circ}$ ), sin perjuicio de que en virtud de esta última disposición pudiera extenderse la aplicación de la garantía, aun sin necesidad de la exigencia de juramento, pero sólo a condición de que en la especie se vea comprometida la libertad personal y la seguridad individual de un modo similar a como lo hace un procedimiento penal (considerandos $13^{\circ}, 15^{\circ}, 18^{\circ}$ y $\left.19^{\circ}\right)^{55}$. Adicionalmente, afirma que, si bien existe consenso en cuanto a la posibilidad de reconocerles titularidad de derechos fundamentales a las personas jurídicas, también lo habría en cuanto a que esto sólo es posible cuando la naturaleza del derecho o interés lo justifiquen (considerando 21\%). Más aún, que el reconocimiento de derechos a las personas jurídicas es excepcional y restrictivo (considerando

${ }^{53}$ Esto en virtud de lo dispuesto en los artículos 385 inciso $1^{\circ}$ y 394 CPC., cuerpo legal aplicable en forma supletoria en la materia en virtud del artículo 29 del Decreto Ley No 211.

${ }^{54} \mathrm{El}$ representante también recurrió por sí mismo, haciendo presente que su declaración compulsiva en calidad de representante legal en este procedimiento también podía tener consecuencias desfavorables para él en otros procedimientos dirigidos personalmente en su contra, pero en esa parte el requerimiento fue considerado inadmisible, por no ser él parte en la gestión pendiente.

${ }^{55}$ Esta clara línea argumental se desdibuja cuando el tribunal agrega que el Tribunal de la Libre Competencia sólo ejerce funciones jurisdiccionales y no administrativo-sancionatorias, de suerte que no le serían aplicables los principios desarrollados por la jurisprudencia del Tribunal Constitucional en materia de sanciones administrativas (considerando $17^{\circ}$ ), argumento desconcertante (¿es que no son aplicables esos principios a las decisiones de los tribunales penales, que manifiestamente ejercen funciones jurisdiccionales?) que desvía la atención del meollo del asunto, cual es el status especial de la garantía contra la auto-incriminación. Lo critica también en su comentario del fallo Cordero, Eduardo, La garantía de no autoincriminación y el poder punitivo del Estado, en El Mercurio Legal, 6 de septiembre de 2013. 
$22^{\circ}$ y $\left.23^{\circ}\right)^{56}$. Y en concreto concluye: "Que, en el caso de autos, el numeral $7^{\circ}$ del articulo 19 versa sobre libertad personal y seguridad individual y ambos derechos no pueden atribuirse a personas jurídicas sin alterar de modo sustantivo su contenido. La libertad personal tutela el derecho de una persona de residir y permanecer en cualquier lugar de la República, trasladarse de uno a otro y entrar y salir de su territorio. La seguridad individual impide la privación de la libertad personal o su restricción fuera de los casos o sin respetar la forma determinada por la Constitución y las leyes. Ambos derechos fundamentales, en armonía con su concepción constitucional, no pueden reconocerse a personas juridicas sin introducir modificaciones en el contenido esencial tutelado. Por su parte, la letraf) del numeral $7^{\circ}$ del artículo 19 ofrece protección en un ámbito particular de la esfera cubierta por la garantía de la libertad personal y de la seguridad individual. Al hacerlo ratifica su propósito de proteger a personas naturales, toda vez que emplea los términos 'hecho propio' y 'ascendientes, descendientes, cónyuge', los que no pueden aplicarse en su significado propio a personas jurídicas. Lo anterior conduce a afirmar que no es aceptable que la persona jurídica EA S.A. resulte tutelada por una garantía concebida para la protección de la libertad personal y seguridad individual de personas naturales" (considerando 24\%).

Como se puede apreciar, la sentencia se funda decisivamente en una peculiaridad del texto constitucional chileno, que trata la garantía contra la auto-incriminación (o al menos contra su forma más burda) separadamente de las garantías procesales generales, asociándola de modo específico a la protección de la libertad y seguridad personales. Que esto deba implicar necesariamente que de ningún modo puede tener aplicación en procedimientos sancionatorios que no comprometan tales derechos (incluso, eventualmente, procedimientos penales conducentes a penas privativas de otros derechos ${ }^{57}$ ) es sin duda discutible ${ }^{58}$, pero lo que interesa destacar aquí es que el tribunal también se haya hecho cargo especialmente de la naturaleza del sujeto en cuestión, como es la constante en el debate comparado, y haya fundado en ella el desconocimiento del derecho con-

${ }^{56}$ No comparte este criterio, no obstante concurrir al fallo el Ministro Aróstica.

${ }^{57}$ Bien lo apunta Cordero, Eduardo, cit. (n. 55).

${ }^{58}$ Que el principio "nemo tenetur" sólo tenga vigencia en materia penal (incluyendo manifestaciones de otros ordenamientos sancionatorios que sean asimilables en concreto al penal) es algo habitual en el derecho comparado y en la jurisprudencia internacional en materia de derechos humanos (por ejemplo, sobre el sistema europeo, Trechsel, Stefan, cit. (n. 3), p. 349; sobre lo que se entiende por "cargo criminal” en los términos del artículo $6^{\circ} \mathrm{CEDH}$, p. 16 ss.), pero no tiene por qué ser forzosamente así. En cambio, no sería usual la distinción entre distintos procedimientos penales. 
tra la auto-incriminación, con lo cual su conclusión resulta plenamente aplicable también en sede penal.

A la hora de la valoración, al margen de algunos argumentos adicionales poco felices ${ }^{59}$, la solución de la sentencia es fundada y convincente, en tanto que, como se ha podido ver, no se encuentra en absoluto aislada en el concierto comparado. Más aún, aquí se sostendrá que materialmente es la solución correcta, por las razones que se pasan a exponer.

\section{Las razones contra un derecho a no auto-incriminarse de las personas} jurídicas.

a) ¿Pertinencia en virtud de normas que no distinguen? No obstante el panorama jurisprudencial esbozado, en la literatura europeocontinental parece ser mayoritaria la posición favorable al reconocimiento de un derecho a la no auto-incriminación de las personas jurídicas, en buena medida simplemente a partir de la idea de que si el derecho penal se extiende a éstas, naturalmente deberían extenderse también a su respecto todas y cada una de las garantías jurídico-penales sin distinción, casi como manifestación de la igualdad ante la ley ${ }^{60}$, invocándose a menudo normas internacionales o constitucionales que, como es el caso del ya citado artículo $34 \mathrm{CEDH}$., no distingue explícitamente entre personas naturales y jurídicas a la hora de consagrar derechos fundamentales ${ }^{61}$.

Con independencia de cuál sea la respuesta correcta a la pregunta que motiva este trabajo, es indudable la debilidad de semejante argumento, pues existe amplio consenso al menos en cuanto a que el eventual reconocimiento de garantías fundamentales a las personas jurídicas está condicionado en todo caso por la naturaleza del derecho en cuestión y del sujeto cuya titularidad sobre el mismo se discute ${ }^{62}$. Así, nadie pretende que las

${ }^{59}$ Como que la absolución de posiciones obligatoria bajo juramento no tendría carácter coactivo (considerandos $25^{\circ}$ a $28^{\circ}$ ), que la declaración del representante que declara en esa precisa calidad no recaería sobre hechos propios del representado (considerando $29^{\circ}$ ) o el ya mencionado recurso al carácter jurisdiccional de las actuaciones del Tribunal de la Libre Competencia (considerando $17^{\circ}$ ).

${ }^{60}$ Así, por ejemplo, para el derecho austriaco: KöcK, Elisabeth, Nemo-teneturGrundsatz für Verbände? en Grafl, Christian - Medigovic, Ursula (editores), Festschrift für Manfred Burgstaller (Wien - Graz, NW Verlag, 2004), pp. 274 ss., y es lo habitual en varios autores que, por lo mismo, no se citarán especialmente aquí.

${ }^{61}$ En ese sentido (en relación con el entonces artículo 25, hoy $34 \mathrm{CEDH}$ ), por ejemplo, WeIss, Wolfgang, Der Schutz des Rechts auf Aussageverweigerung durch die EMRK, en NJW. (1999), p. 2237; SCHULER, Patrick, Zur Diskussion um ein Aussageverweigerungsrecht juristischer Personen, en JR. 2003, p. 270.

${ }^{62}$ En la literatura constitucional chilena, por todos, Aldunate, Eduardo, Derechos fundamentales (Santiago, LegalPublishing, 2008), pp. 157 s. 
personas jurídicas puedan ser titulares del derecho a la vida o del derecho a la integridad física y psíquica (artículo 19 No 1 CPPol.), del derecho a la educación (artículo 19 No 10 CPPol. o del derecho de reunión (artículo 19 No 13 CPPol.). Por lo mismo, la circunstancia de que los textos en cuestión "no distingan" entre personas naturales y jurídicas a la hora de consagrar un derecho no libera de la necesidad de justificar especialmente su pertinencia respecto de las personas jurídicas ${ }^{63}$.

Hay al menos dos maneras de entender este necesario examen de pertinencia o compatibilidad. La primera es entender que el derecho es pertinente para las personas jurídicas simplemente cuando mutatis mutandis sea imaginable alguna forma de ejercicio del mismo por parte de ellas. La segunda es entender que hay pertinencia cuando respecto de la persona jurídica se dan, además, las razo nes en que se funda el derecho o garantía.

Como es obvio, sólo la segunda lectura puede ser correcta, pues la primera no provee ningún criterio de justificación. Así, mediante la equiparación de menoscabos que sólo pueden sufrir las personas naturales con situaciones diferentes pero de algún modo similares que sí son posibles respecto de las personas jurídicas se podría entender, por ejemplo, que una pena de disolución, que de algún modo "equivale" a la pena de muerte, está sometida a las mismas restricciones que rigen para esta última pena (cfr. artículo $4 \mathrm{CADH}$.); o mediante el fácil expediente de hacer de derechos del representante derechos de la persona jurídica, todos los derechos fundamentales serían pertinentes respecto de los entes colectivos y habría que admitir, por ejemplo, que la persona jurídica tiene derecho a no ser torturada en la medida en que su representante tiene derecho a no ser torturado, lo que es a todas luces absurdo, sin contar con el potencial grave menoscabo de los derechos del representante que podría llegar a justificar la aplicación consecuente del razonamiento en sentido inverso, como sería, por ejemplo, que se pudiera someter a prisión preventiva al representante cuando se cumplieran los presupuestos de la misma respecto de la persona jurídica representada. Obviamente se trata de exageraciones que los partidarios de una lectura amplia con seguridad no querrían defender, pero la única manera segura de evitar resultados absurdos es abandonar la primera lectura y asumir la segunda, para la cual lo único decisivo es la ratio de la garantía en cuestión.

Y como se argumentará a continuación, desde esta perspectiva hay buenas razones para negar que el derecho a no auto-incriminarse sea pertinente respecto de las personas jurídicas.

${ }^{63}$ Así, correctamente, respecto del citado artículo 34 CEDH.: van KEMPEN, Piet Hein, cit. (n. 9), pp. 11 ss. 
b) El fundamento del derecho y su impertinencia respecto de las personas jurídicas. Existe una ardua discusión sobre el fundamento del derecho a no auto-incriminarse que no es posible abordar aquí, ni aun limitadamente. Con todo, resulta bastante claro que en su origen, al margen de las controversias que también existen al respecto ${ }^{64}$, se encuentra la preocupación por la situación extrema de conflicto en que se pone al imputado obligado a colaborar con la acusación en su contra. Todas las hipótesis históricas coinciden en que el surgimiento del derecho respondió a la consolidación de la idea de que un deber de declarar contra sí mismo representaba un método de indagación inicuo, inmoral y brutal, en alguna medida equivalente a la tortura. De lo que en definitiva se trataba era, entonces, de no someter al imputado al "cruel dilema" de optar entre contribuir a su propia condena, mentir (lo que en algunas tradiciones jurídicas importa cometer un delito, aunque se tenga la calidad de imputado) o incurrir en desacato, trato que constituye una suerte de tortura moral y, en todo caso, un trato degradante, incompatible con el respeto de la dignidad humana. No debe sorprender entonces que la jurisprudencia comparada (tal como la chilena recientemente) suela basarse, como se ha visto, explícitamente en la evitación de ese conflicto $\mathrm{y}$ en los derechos o atributos individuales comprometidos en el mismo (intimidad, libertad, dignidad, etc.) para justificar todavía en la actualidad la protección contra la auto-incriminación.

Particularmente en la literatura alemana, no obstante dominar en ella la tesis que ve el fundamento de la protección contra la auto-incriminación en la dignidad humana y en el derecho de la personalidad, precisamente a partir del conflicto aludido, ésta ha sido motejada de "naturalística" y

${ }^{64}$ Sobre la disputa desde el punto de vista de la situación de las personas jurídicas puede verse en Trainor, Scott A., cit. (n. 12), pp. 2141-2163; una síntesis más apretada en Loschin, Lynn, A Comparative Law Approach to Corporations and the Privilege Against Self-Incrimination, en U.C. Davis Law Review, 30 (1996-1997), pp. 250 ss. Para el debate mismo véase, por una parte, LevY, Leonard W., Origins of the Fifth Amendment and Its Critics, en Cardozo Law Review, 19 (1997-1998), pp. 821 ss.; y, por la otra, Helmholz, H.M.: Origins of the Privilege Against Self-Incrimination: The Role of the European "Ius Commune", en N.Y.U. Law Review, 65 (1990), pp. 962 ss.; Langbein, John H., The Historical Origins of the Privilege Against Self-Incrimination at Common Law, en Mich. Law Review, 92 (1993-1994), pp. 1047 ss.; Moglen, Eben, Origins of the Constitutional Privilege Against Self-Incrimination, en Mich. Law Review, 92 (1993-1994), pp. 1086 ss. Desde perspectiva europeo-continental, asumiendo la importancia decisiva de la tradición anglosajona para el nacimiento del derecho, BösE, Martin, Wirtschaftsaufsicht und Strafverfolgung (Tübingen, Mohr Siebeck, 2005), pp. 150 ss. 
"psicologicista" 65 , dando paso a elaboraciones conceptuales estrictamente normativas, que pretenden superar ciertas debilidades y vacíos (reales) de una tesis que a veces parece responder más a una intuición que a una deducción rigurosa ${ }^{66}$. En la medida en que alguno de esos desarrollos independice el asunto de la encrucijada dramática en que se encuentra el imputado, es perfectamente posible extender a las personas jurídicas el derecho a no auto-incriminarse ${ }^{67}$. No parece, sin embargo, que pueda ser correcta una elaboración conceptual del derecho a no auto-incriminarse que prescinda del conflicto aludido y de su valoración como intolerable desde la perspectiva de la experiencia sensible de los hombres ${ }^{68}$, en circunstancias que es precisamente desde ese conflicto y su valoración que

${ }^{65}$ Así, entre otros: BÖSE, Martin, cit. (n. 64), pp. 136 ss., con abundantes referencias; Queck, Nadine, Die Geltung des nemo-tenetur-Grunsatzes zugunsten von Unternehmen (Berlin, Duncker \& Humblot, 2005, pp. 119 ss., 147 ss.; VON FreIER, Friedrich, Selbstbelastungsfreiheit für Verbandpersonen? en ZStW., 122 (2010), pp. $128 \mathrm{~s}$.

${ }^{66}$ Sin perjuicio de que se pueda afirmar que no se trata de la simple evitación de situaciones conflictivas desde un punto de vista psicológico, sino del trato que un Estado de Derecho le debe a un sujeto dotado de dignidad en el establecimiento de una posible responsabilidad penal, trato que debe evitar una situación objetiva de conflicto extremo, con independencia de su concreta incidencia en la situación psicológica del sujeto (un buen paralelo de esto en el derecho penal sustantivo es la regulación del estado de necesidad exculpante, que atiende exclusivamente a la situación objetiva de conflicto en que se encuentra el sujeto, sin exigir un estado de conmoción o angustia relevante en él). Por eso no convencen las objeciones de VON FREIER, Friedrich, cit. (n. 65), p. 129: que la garantía proteja también a los inocentes, que rija también respecto de penas leves o que en muchos ordenamientos jurídicos no se pueda dar valor probatorio al silencio del imputado son consecuencias de la definición de las condiciones normativas de evitación del conflicto, no de los efectos psicológicos del mismo. Lleva razón, sin embargo, en cuanto a que los límites que en virtud del principio "nemo tenetur" se le ponen a la acción de agentes encubiertos no se dejan explicar por la evitación del mencionado conflicto, pero a eso habría que decir que, precisamente, esas limitaciones son una peculiaridad del derecho alemán y que, en efecto, poco tienen que ver con el principio en cuestión.

${ }^{67}$ Es, por ejemplo, lo que hace Böse, Martin, cit. (n. 64), pp. 149 ss., 166 ss., quien concibe el principio "nemo tenetur" como manifestación del derecho a ser oído en perspectiva de derecho de defensa (tesis anticipada en BösE, Martin, Die verfassungsrechtliche Grundlagen des Satzes "Nemo tenetur se ipsum accusare", en GA. (2002), pp. 98 ss.), razón por la cual no extraña que lo reconozca también para las personas jurídicas (pp. 196 s.); y siguiéndolo ostensiblemente, QUECK, Nadine, cit. (n. 65), pp. 181 ss., 214 ss.

${ }^{68}$ Siguiendo con el paralelo del estado de necesidad exculpante, que se formalicen sus presupuestos y no se exija ninguna conmoción psíquica en el sujeto, no altera la circunstancia de que los presupuestos formalizados han sido definidos y valorados como lo han sido a partir de experiencias sensibles extendidas. 
surge el derecho. Si esto es efectivamente así, entonces bajo cualquier elaboración conceptual correcta del derecho debería ser cierto que éste no es pertinente respecto de personas jurídicas, incapaces por definición de experimentar el conflicto ${ }^{69}$.

Otro sector de la literatura alemana, que coincide en derivar de la dignidad humana el derecho contra la auto-incriminación, sostiene, sin embargo, que el reconocimiento de una genuina responsabilidad penal de las personas jurídicas supone forzosamente que también se les reconoce una cierta dignidad, con lo cual decaería la objeción basada en su carencia de tal atributo ${ }^{70}$. Pero no hay sólo un fundamento de la responsabilidad penal de las personas jurídicas que sea compatible con el orden constitucional, a menos, claro está, que se asuma (y no simplemente en el plano teórico, sino también en el de la vigencia normativa) que sólo puede ser derecho penal algo que de algún modo satisface los presupuestos y garantías que rodean la responsabilidad penal de las personas naturales, olvidando que, al margen de cuestiones orgánicas, el único límite normativo de las decisiones del legislador democrático viene dado por las garantías fundamentales, garantías que son de las personas y no del derecho penal. En consecuencia, lo que estos autores deberían demostrar es precisamente lo que dan por supuesto, esto es, que las personas jurídicas gozan también de la garantía jurídico-penal en cuestión. En este contexto, no deja de ser llamativo que críticos acérrimos de la responsabilidad penal de las personas jurídicas, que la consideran incompatible con los presupuestos y garantías del derecho penal individual, único objeto digno a su juicio de la denominación, pero que asumen que, una vez establecida, no podrían

${ }^{69}$ Ésta es la opinión que, sobre la base de una visión tradicional del fundamento del derecho, sostienen, entre otros: RANSIEK, Andreas, Unternehmensstrafrecht (Heidelberg, C.F. Müller, 1996), pp. 357 ss., 360; y (desde Suiza) ARzT, Gunther, Schutz juristischer Personen gegen Selbstbelastung, en JZ. (2003), p. 457.

${ }^{70}$ SCHLÜTER, Jan, Die Strafbarkeit von Unternehmen in einer prozessualen Betrachtung nach dem geltenden Strafprozeßrecht (Frankfurt a. M., Peter Lang, 2000), pp. 112 ss., 119; también, aunque menos enfática (sólo sería lo "consecuente" para quienes de algún modo fundan la procedencia de una responsabilidad penal de las personas jurídicas en una "personalidad” de las mismas) Drope, Katharina, Strafprozessuale Probleme bei der Einführung einer Verbandsstrafe (Berlin, Duncker \& Humblot, 2002), pp. 199, 202; y, si bien pretende fundarlo ex profeso en el Estado de Derecho y no en la dignidad humana, en cuanto conecta automáticamente responsabilidad penal con culpabilidad y reproche ético y éstos con derecho a no auto-incriminarse, DANNECKER, Gerhard, Beweiserhebung, Verfahrensgarantien und Verteidigungsrechte im europäischen Kartellordnungswidrigkeitenverfahren als Vorbild für ein europäisches Sanktionsverfahren, en ZStW., 111 (1999), p. 286. 
desconocerla, derivan precisamente de ello que las personas jurídicas no tienen derecho a no auto-incriminarse ${ }^{71}$.

Por último, se ha hecho presente que aunque la persona jurídica en cuanto tal no pueda experimentar el conflicto que justifica la protección contra la auto-incriminación, sí lo enfrentan las personas naturales que actúan por ell ${ }^{72}$, con lo cual, sin embargo, se pasa por alto que en tal caso se trata de una situación del todo diferente, pues el representante no corre el riesgo de incriminarse a sí mismo, sino que al ente que representa (sin que exista a su respecto, obviamente, un vínculo familiar como el que justifica la ampliación del derecho a ciertos parientes cercanos), en tanto que si eventualmente corriera riesgo, podría hacer valer su propio derecho contra la auto-incriminación.

Esta íntima conexión de la garantía con la naturaleza de su titular constituye la diferencia más notoria con otras garantías que, en general, se reconocen sin dificultad también a las personas jurídicas, porque en rigor son garantías que tienen sentido respecto de cualquiera. Si se recuerdan, por ejemplo, las garantías judiciales que el Tribunal Europeo de Derechos Humanos les ha reconocido a las personas jurídicas, es claro que se trata de garantías para las cuales resulta totalmente indiferente la naturaleza del titular. Tener derecho a un tribunal imparcial o a ser oído por el mismo en igualdad de condiciones que la contraparte son elementos constitutivos de cualquier procedimiento legítimo, de modo que no puede sorprender que sean garantías que benefician a cualquiera, también a las personas jurídicas. Pero tratándose del derecho a no auto-incriminarse, tendiente a evitar una situación de conflicto que como tal sólo puede experimentar una persona natural, ciertamente no puede decirse lo mismo.

c) ¿Pertinencia vía deberes estatales de corrección o vía principios procesales? En vez de invocarse un derecho subjetivo de las personas jurídicas frente a la compulsión estatal a su colaboración en el procedimiento penal seguido en su contra, podrían todavía invocarse ciertos supuestos deberes básicos de corrección procesal que el Estado tendría que respetar en todo caso, aun cuando no existiera un derecho correlativo. Ésta es la lógica que subyace, por ejemplo, en la jurisprudencia estadounidense sobre "entrampamiento" ("entrapment") ${ }^{73} \mathrm{o}$ en ciertas formas de invoca-

${ }^{71}$ Es el caso de vON FrEIER, Friedrich, cit. (n. 65), pp. 136 ss., por considerar que la responsabilidad penal de la persona jurídica prescinde de culpabilidad, mismo atributo que se expresaría en el diálogo constitutivo del proceso penal y a cuya preservación debiera servir el principio "nemo tenetur".

${ }^{72}$ WeIss, Wolfgang, Haben juristische Personen ein Aussageverweigerungsrecht? en JZ. (1998), p. 296; SCHUler, Patrick, cit. (n. 61), p. 268.

${ }^{73}$ Particularmente en su concepción "objetiva”; al respecto, en general, DrESSLER, 
ción del "principio del Estado de Derecho" ("Rechtsstaatsprinzip" o simplemente "Rechtsstaatlichkeit") por parte de la jurisprudencia alemana. Y, en efecto, parte de la literatura alemana deriva de este principio el derecho contra la auto-incriminación, con la consecuencia de resultar éste aplicable respecto de cualquier imputado, también respecto de personas jurídicas ${ }^{74}$.

$\mathrm{Al}$ margen de cualquier discusión sobre la procedencia de desarrollos como éstos en el derecho constitucional vigente en Chile, lo decisivo es que su aplicación supondría que hubiera algo moralmente objetable en que el Estado exija la colaboración de un imputado a quien no se le vulnera ninguna garantía con ello, como si hubiera algo per se indebido en una persecución penal más expedita y eficaz. Todo indica, sin embargo, que lo indebido en la compulsión a la auto-incriminación no radica ni en los propósitos ni en el potencial resultado efectivamente incriminatorio, sino sólo en el trato degradante que recibe el imputado, consistente no ya en prescindir de su voluntad o incluso proceder en contra de ella (no otra cosa es la entrada en su vivienda, el registro de la misma, la incautación de sus pertenencias o el sometimiento de su cuerpo a ciertas actividades de investigación, todas actividades que pueden realizarse aun contra su voluntad), sino que en ponerlo en la encrucijada de tener que optar entre males graves para sí mismo. $\mathrm{Y}$ si de esto se trata, entonces es evidente que las razones del derecho a la no auto-incriminación sólo rigen respecto de las personas naturales, no de construcciones jurídicas que simplemente no pueden experimentar como tal dicha encrucijada.

Una manera levemente diferente de ver el asunto consistiría en entender que, aunque no hubiera ninguna garantía comprometida ni pudiera reprochársele nada incorrecto a la actuación estatal, la renuncia a la colaboración de la persona jurídica imputada viene impuesta por la lógica de un proceso penal de carácter acusatorio y contradictorio, especialmente en lo concerniente a la formación de la prueba ${ }^{75}$. Este razonamiento tiene

Joshua, Understanding Criminal Procedure ( $3^{a}$ edición, Newark - San Francisco, LexisNexis, 2002), pp. 579 ss., 586 ss.

${ }^{74}$ Haeusermann, Axel, Der Verband als Straftäter und Strafprozeßsubjekt (Freiburg i. Br., Edition Iuscrim, 2003), pp. 342 s., 350; Minoggio, Ingo, Das Schweigerecht der juristischen Person als Nebenbeteiligte im Strafverfahren, en Zeitschrift für Wirtschafts- und Steuerstrafrecht (2003), p. 128; y antes, si bien con el matiz apuntado, DANNeCKer, Gerhard, cit. (n. 70), p. 286.

${ }^{75}$ Lo que en algún ordenamiento tiene incluso rango constitucional (por ejemplo, en el artículo 111 de la Constitución italiana). El argumento ha aparecido también en la discusión anglosajona, por ejemplo, en la sentencia de la Corte Suprema australiana en el caso "Caltex" ([1993] HCA 74, a partir del apartado 37 del voto de los jueces Mason y Toohey y del apartado 30 del voto del juez McHugh). En esta línea se inscribe también, para el derecho suizo, PieTH, Mark, Strafverfahren gegen 
más fuerza, pues aunque en Chile difícilmente se le pueda atribuir rango constitucional a principios procesales que no encarnen al mismo tiempo derechos fundamentales de los justiciables, con lo cual la derivación de un "derecho" de las personas jurídicas a la no auto-incriminación a partir de esa fuente carecería de anclaje en la Constitución, al menos debe reconocerse que resulta incoherente un procedimiento contradictorio en que la parte acusadora puede imponerle a la acusada el deber de colaborar con la acusación. Como se verá luego, sin embargo, la incoherencia sólo es efectiva en un espacio relativamente marginal, y más que justificar en general un derecho a no auto-incriminarse de las personas jurídicas, sugiere más bien la necesidad de poner ciertos límites al deber general de colaboración de quienes actúan por ellas ${ }^{76}$.

d) Las dificultades prácticas específicas debidas al carácter artificial del sujeto. A nadie puede escapar que las razones principales contra el reconocimiento de un derecho de las personas jurídicas a la no auto-incriminación son de naturaleza práctica. La persecución penal de las personas jurídicas se resentiría enormemente si los individuos que se desempeñan en ellas y que poseen información relevante sobre los hechos pudieran abstenerse de declarar o, sobre todo, de entregar documentación u otros objetos en virtud de este derecho, tanto más si el círculo de sujetos con esa prerrogativa se define extensivamente ${ }^{77} \mathrm{o}$ si la prerrogativa se extiende hasta alcanzar el ocultamiento o la destrucción de información, todo lo cual es conceptualmente posible una vez que se reconoce el derecho ${ }^{78}$. Como ha hecho presente alguna jurisprudencia extranjera, dicho reconocimiento podría hacer ilusoria, no sin paradoja, la decisión misma del legislador de imponer sanciones penales a las personas jurídicas ${ }^{79}$.

Ahora bien y como es obvio, las dificultades prácticas que, por definición, acarrean las garantías procesales para la persecución penal no pueden ser argumento válido para suspender la vigencia de dichas garantías, ni aun en contextos específicos en los que la investigación criminal resulta

das Unternehmen, en ARNOLD, Jörg y otros (editores), Menschengerechtes Strafrecht. Festschrift für Albin Eser (München, Beck, 2005), pp. 605 ss.

${ }^{76}$ Es la recomendación metodológica de ARZT, Gunther, Schutz juristischer Personen, cit. (n. 69), pp. 458 s.

${ }^{77}$ Como se verá luego, en el derecho suizo alcanza a todos los trabajadores de la empresa.

${ }^{78}$ Sobre esto ARZT, Gunther, Schutz juristischer Personen, cit. (n. 69), p. 458.

${ }^{79}$ Por ejemplo, de nuevo en el caso Caltex ([1993] HCA 74, apartado $12 \mathrm{del}$ voto del juez Brennan); y sobre las catastróficas consecuencias para las agencias administrativas de vigilancia: ARZT, Gunther, Strafuerfahren ohne Menschenrechte gegen juristische Personen, en Grafl, Christian - Medigovic, Ursula (editores), Festschrift für Manfred Burgstaller (Wien - Graz, NW Verlag, 2004), pp. 230 s. 
especialmente ardua y compleja, como es el caso tratándose de la delincuencia de empresa ${ }^{80}$. Por cierto podría ser más eficiente una persecución penal que no reconociera límites en los derechos de las personas, pero sería indigna de un Estado de Derecho.

Ahora bien, aun siendo esto indudable, admite un importante matiz, porque en este contexto particular el derecho a no auto-incriminarse genera dificultades prácticas específicas y adicionales, condicionadas estructuralmente por la naturaleza del sujeto imputado y que no son comparables con las que normalmente provoca el mismo derecho tratándose de personas naturales, lo que constituye una razón decisiva contra la equiparación.

En efecto, mientras que la persona natural imputada que ejerce su derecho a guardar silencio es una y siempre la misma, tratándose de una persona jurídica el derecho se ejerce necesariamente a través de personas naturales que pueden ser varias, sea simultáneamente (si se permite que varios puedan tener la prerrogativa al mismo tiempo), sea de modo consecutivo (a través de reemplazos). Como es obvio, esto encierra tanto un riesgo de sobreprotección, en el sentido de que las personas con derecho a no colaborar y hasta a obstaculizar la acción de la justicia penal no se reducen necesariamente a un único (y siempre el mismo) sujeto, sino que pueden ser muchos, como también un riesgo de manipulación, pues quienes deciden por la persona jurídica pueden decidir también, libremente y en cualquier momento, quién o quiénes tendrán la prerrogativa, y esto sobre la base de criterios imposibles de controlar desde la perspectiva de su legitimidad. Ambos riesgos están excluidos por completo respecto de una persona natural, con lo cual queda claro que no se trata de dificultades prácticas inherentes al ejercicio legítimo del derecho, sino que de dificultades adicionales ajenas a la lógica del mismo, derivadas exclusivamente del carácter artificial del sujeto y que, por lo tanto, no hay por qué tolerar.

\footnotetext{
${ }^{80}$ Como, por ejemplo, lo destaca certeramente el Tribunal Europeo de Derechos Humanos en la sentencia del citado caso "Saunders", donde precisamente se analizaba la vulneración del derecho a no auto-incriminarse de un directivo de empresa: "[la Corte] no acepta el argumento del Gobierno de que la complejidad del fraude corporativo y el vital interés público en la investigación de dicho fraude y el castigo de sus responsables justificaría un alejamiento tan marcado como el que ocurrió en este caso de uno de los principios básicos de un procedimiento justo... considera que la exigencia de justicia contenida en el Artículo 6, incluyendo el derecho a no auto-incriminarse, es aplicable a los procedimientos penales respecto de todos los tipos de ofensas criminales sin distinción, desde la más simple hasta la más compleja" (considerando $74^{\circ}$ ).
} 


\section{III. ¿QUUE IMPLICARÍA EN RIGOR}

UN DERECHO DE LA PERSONA JURÍDICA A NO AUTO-INCRIMINARSE?

Como se ha podido ver, la discusión se ha dado en términos binarios y abstractos de afirmación o negación del derecho en cuestión para las personas jurídicas, predominando una cierta tendencia favorable a su negación, lo que aquí se comparte por las razones precedentemente expuestas. Llama la atención, sin embargo, que en el debate casi no se expliciten los alcances concretos de lo que se está discutiendo. Tal explicitación permitiría advertir que el campo de lo controvertible es mucho más estrecho de lo que aparenta ser, de modo que, aunque se admitiera, en contra de lo sostenido aquí, un derecho a no auto-incriminarse de las personas jurídicas, éste debería tener unos alcances prácticos más bien modestos, similares a los de restricciones del deber general de colaboración que los detractores de semejante derecho probablemente estarían dispuestos a aceptar. Esto es lo que se intentará demostrar en las páginas siguientes.

\section{El único supuesto problemático y su modesto remedio.}

La sola pregunta por un derecho de la persona jurídica a la no autoincriminación requiere de cierta precisión para ser inteligible. En la medida en que la persona jurídica por su propia naturaleza no hace ni puede hacer nada por sí misma, tampoco está en condiciones de auto-incriminarse ${ }^{81}$, de modo que cuando a su respecto se habla de "auto-incriminación" necesariamente se está hablando de la conducta de personas naturales, de terceros, cuya actuación bajo ciertas circunstancias se atribuye a la persona jurídica como si fuera conducta propia de ella, en este caso con efectos incriminatorios. Esto determina que cuando se discute sobre un derecho de las personas jurídicas a no auto-incriminarse la cuestión es siempre, en rigor, si a esos terceros se les reconocerá, y en caso afirmativo bajo qué condiciones y en qué medida, el derecho a negarse a colaborar con la persecución penal amparándose en el supuesto derecho a hacerlo de la persona jurídica imputada.

Ahora bien, la precisión pone al mismo tiempo en evidencia que los supuestos para los cuales realmente tiene sentido la discusión de un derecho a no auto-incriminarse de la persona jurídica son mucho más acotados que lo que la polémica sugiere. Si los únicos casos en que el comportamiento de un tercero puede considerarse comportamiento propio de la persona jurídica $-y$ puede haber, en consecuencia, una eventual "auto-

${ }^{81}$ En palabras de ARZT, Gunther, Schutz juristischer Personen, cit. (n. 69), p. 457: no es evidente que deba tener derecho a guardar silencio quien no puede hablar. 
incriminación" de la misma- son aquéllos en que el tercero actúa en su nombre y representación, entonces la única vulneración posible de un tal derecho se daría cuando se obligara al representante a colaborar con la investigación y el enjuiciamiento de la persona jurídica en esa precisa calidad de representante, es decir, representándola.

Porque, en efecto, tal como la persona jurídica hace alegaciones o presenta pruebas a través de su representante, también puede colaborar con la investigación y hasta reconocer su responsabilidad a través del mismo ${ }^{82}$, de modo que, de tenerlo, se conculcaría su derecho a no auto-incriminarse si se le negara a su representante el derecho a no colaborar en su nombre y representación, porque en tal caso, en la medida en que el acto del representante vale como acto del representado, sería la propia persona jurídica la que se estaría incriminando mediante su representante y de modo compulsivo.

Más allá de este supuesto, en cambio, simplemente no puede hablarse de auto-incriminación ni menos de un derecho en su contra. En el resto de los casos, la persona jurídica no necesita un derecho a no auto-incriminarse por la sencilla razón de que nunca podrá hacerlo (ni menos ser obligada a hacerlo). Se trataría de un derecho que no puede ser conculcado, porque su objeto es evitarle a la persona jurídica una situación en la que, por razones estructurales y salvo la excepción ya mencionada, nunca podrá encontrarse. Los únicos que pueden incriminar a la persona jurídica son terceros que, salvo en el mencionado caso excepcional, actúan como tales. Y, como se sabe, no existe un derecho contra la incriminación de parte de terceros.

Entonces, desde el punto de vista de un derecho de la persona jurídica a la no auto-incriminación la solución es tan simple como acotada: basta con que se le asegure al representante de la persona jurídica el derecho a no colaborar con la investigación en nombre y representación de ésta. En todo lo demás, en cuanto tercero que es, no hay razones para sustraer al representante del régimen general de los terceros en el proceso penal, en concreto del deber de colaborar en todo lo que pueda ser útil para la investigación y el enjuiciamiento: si el tercero tiene información relevante es un testigo y como tal está obligado a declarar y a decir verdad, en tanto que si tiene en su poder documentos u otros objetos relevantes está obligado a manifestarlos o entregarlos, en uno y otro caso bajo apercibimiento de medidas de apremio o sanción para el evento de incumplimiento.

Si bien se mira, esto es lo mismo que rige para el representante de una persona natural: sin duda está obligado a declarar bajo juramento o promesa

${ }^{82}$ Caso en el cual incluso se le reconoce una atenuante (artículo $11 \mathrm{~N}^{\circ} 9 \mathrm{CP}$. vía artículo $6^{\circ} \mathrm{N}^{\circ} 2$ de la Ley $\mathrm{N}^{\circ} 20.393$ ). 
de decir verdad sobre hechos que pueden perjudicar a su representado, sin contar con otras formas de colaboración igualmente perjudiciales para el mismo, pero nadie pretendería que también fuese obligado a declarar al respecto en su calidad de representante, es decir, ejerciendo la representación y vinculando de ese modo al imputado. Tratándose de personas naturales imputadas esto ni siquiera se menciona, simplemente porque su declaración en materia penal es un acto personalísimo que no admite representación, pero tratándose de una persona jurídica imputada, a la que se le reconoce el derecho a declarar en cualquier momento como medio de defensa o de decir la última palabra, derecho que sólo puede ejercer a través de su representante porque es estructuralmente incapaz de ejercer sus derechos personalísimos por sí misma ${ }^{83}$, la posibilidad de auto-incriminación a través de actuaciones del representante en nombre y representación del representado pasa a ser algo normal y requiere regulación, en concreto, si se resuelve que la auto-incriminación compulsiva también es inadmisible en este caso, requiere mecanismos que la eviten. Pero más allá de ese remedio, desde la perspectiva de un derecho a no auto-incriminarse no se aprecia por qué debieran brindársele al representante de la persona jurídica más derechos que los que se le brindan al de una persona natural.

Naturalmente deben regir también para el representante de la persona jurídica en cuanto tercero los límites generales de la carga general de colaborar con las investigaciones y juicios penales, de modo que debe poder negarse legítimamente a hacerlo cuando esto implique riesgo de incriminación para sí mismo, caso en el cual en rigor ejerce su propio y personalísimo derecho a no auto-incriminarse, o bien cuando tiene el deber de guardar secreto por causa legal, como sería el caso del secreto profesional.

Pero por cierto sería absurdo pretender que se extendieran (legalmente o por analogía) a quienes deben atestiguar contra la persona jurídica supuestos de liberación del deber de declarar que se fundan en vínculos que sólo tienen sentido respecto de personas naturales, como son, por ejemplo, los vínculos familiares, y no sólo por la manifiesta impertinencia del fundamento de la causa de liberación en este caso, sino sobre todo porque dicha extensión implicaría poner a esos testigos en mejor situación que los testigos llamados a declarar contra una persona natural, y de ese modo, indirectamente, implicaría poner a las personas jurídicas imputadas en mejor situación que las persona naturales imputadas. Porque, en efecto, tal como el representante de la persona natural no tiene derecho a no declarar

\footnotetext{
${ }^{83}$ Cuando la persona natural imputada no está en condiciones de ejercer sus derechos personalísimos simplemente no hay proceso penal. Al respecto HernÁNDEZ, Héctor, Algunos problemas de la representación de la persona jurídica imputada en el proceso penal, en Doctrina y Jurisprudencia Penal, 10 (2012), p. 4.
} 
contra su representado, tampoco tienen ese derecho sus colegas, socios o empleados, de modo que no se entiende por qué habría de aceptarse que sí tuvieran ese derecho los representantes u otros empleados de la persona jurídica, por mencionar a los sujetos más “cercanos" a ella ${ }^{84}$.

En consecuencia, cualquier derecho adicional a no colaborar con la investigación y el enjuiciamiento de la persona jurídica que se le conceda al representante de la misma ya no se deja justificar en un supuesto derecho de ésta a la no auto-incriminación, sino en otras consideraciones que habrán de evaluarse en su propio mérito, especialmente desde el punto de vista del igual trato que merecen las personas naturales imputadas. Desde ya, aquí se adelanta la opinión contraria a una extensión mayor del supuesto derecho.

\section{Confirmación en un par de legislaciones europeo-continentales (España} e Italia).

Esto explica que, aun en ordenamientos jurídicos abierta o al menos tendencialmente proclives al reconocimiento de un derecho a no autoincriminarse de las personas jurídicas, la concesión de derechos de no colaboración a los representantes de las mismas se dé en grados muy diferentes. Porque el legislador puede ir más allá del contenido conceptualmente necesario de un derecho a no auto-incriminarse de la persona jurídica, consistente en no obligar al representante a colaborar en nombre y representación de la misma. Lo importante aquí es destacar que, cuando lo hace, es por otras razones y no por exigencia de dicho derecho.

Así, mientras algunos ordenamientos favorecen en grado sumo los intereses de las personas jurídicas reconociéndole explícita o implícitamente a su representante (e incluso a otras personas) los derechos propios del imputado o al menos derechos semejantes que incluyen el de no colaborar, como es

\footnotetext{
${ }^{84}$ Como acertadamente ha apuntado Brodowski, Dominik, Minimum Procedural Rights for Corporations in Corporate Criminal Procedure, en BRODOWSKI, Dominik - Espinoza de los Monteros de la Parra, Manuel - Tiedemann, Klaus - Vogel, Joachim (editores), Regulating Corporate Criminal Liability (Cham etc., Springer, 2014), p. 222, la naturaleza jurídica del imputado no puede condicionar las prerrogativas de su representante; sugiere lo mismo ArzT, Gunther, Strafverfahren, cit. (n. 79), p. 229.
} 
el caso de Suiza $^{85}$ o, en menor medida, de Austria ${ }^{86}$, otros ordenamientos,

${ }^{85}$ Las primeras disposiciones procesales previstas al momento de la introducción de la responsabilidad penal de las personas jurídicas en el Código penal helvético en 2003 se encontraban en el artículo 100 quinquies del mismo código, cuyo inciso segundo le confería todos los derechos del imputado al representante designado para los efectos del proceso penal, al tiempo que a los otros posibles representantes (conforme al inciso primero del mismo artículo la persona jurídica debía tener un único representante para los efectos del proceso penal, regla que se mantiene en la actualidad en el inciso primero del artículo $112 \mathrm{CPP}$ ) al menos les confería el derecho a no declarar contra la persona jurídica. El artículo artículo 100 quinquies CP (que pasó a ser artículo 102 a) CP. con la entrada en vigencia de la revisión de la "Parte General" del Código, en 2007) fue suprimido con la entrada en vigencia en 2011 del nuevo Código de procedimiento penal (primer código procesal penal con vigencia nacional, para todos los cantones), que es donde ahora se regula el "procedimiento contra empresas". El artículo 112 CPP no se hace cargo del status del representante de la persona jurídica, pero éste se desprende de la letra g) del artículo 178, que le atribuye tanto al que ha sido designado representante como a quien podría serlo, la calidad de "persona llamada a dar informaciones" (“Auskunftsperson", "personne appelées à donner des renseignements"), es decir, una categoría propia del derecho suizo, que corresponde a personas que si bien poseen información sobre los hechos, exhiben un déficit de credibilidad (por minoría de edad, déficit psíquico o situación objetiva de conflicto, en la línea de las antiguas "tachas"), al punto que no están obligadas a declarar y si declaran deben hacerlo en los mismos términos que el imputado (artículo 180,1 CPP.), ni están obligadas a entregar objetos, sin que puedan ser compelidas a hacerlo (artículo 265,2 letra b CPP.). La misma norma extiende esta calidad también a los empleados de la empresa y del representante (la letra g] del artículo 178 CPP. le atribuye la calidad especial "a quien ha sido designado o podría ser designado como representante de la empresa en un procedimiento penal dirigido contra la empresa, asi como a sus [del representante y de la empresa] empleadas y empleados"), con lo cual se establece un formidable escudo frente a las indagaciones dirigidas contra la persona jurídica, inexistente respecto de personas naturales. Por último, se consagra también un derecho propio de la persona jurídica imputada a negarse a entregar documentos u objetos que pudieran incriminarla [artículo 265.2 letra c) 1 CPP.]. Aunque las disposiciones se entienden por sí solas, puede verse una buena visión sintética del conjunto en Macaluso, Alain, Art. 112, en Kunn, André - Jeanneret, Yvan (editores), Commentaire Romand. Code de procédure pénale suisse (Bâle, Helbing Lichtenhahn, 2011), nn. 40 ss.

${ }^{86} \mathrm{El} \$ 17$ de la Ley de Responsabilidad de las Asociaciones (Verbandsverantwortlichkeitsgesetz: VbVG) de 2005 dispone que el sujeto con poder de decisión en la asociación ("Entscheidungsträger", concepto definido en el $\$ 2 \mathrm{VbVG}$, que abarca a representantes, sujetos con poder de decisión y dirección y otros que ejerzan influencia decisiva en la dirección) debe ser citado e interrogado en calidad de imputado, así como que debe ser advertido de su derecho a guardar silencio (lo mismo rige para los empleados, pero sólo cuando son sospechosos del delito o ya hayan sido condenados por el mismo). Respecto de objetos relevantes, las reglas generales de la ordenanza procesal penal (StPO, aplicables supletoriamente conforme al \$ 14 I VbVG.) obligan 
en cambio, no están dispuestos a renunciar a dicha colaboración más allá del mencionado contenido conceptualmente necesario. Esto resulta particularmente nítido en las regulaciones pertinentes del derecho español e italiano, a pesar de la incomprensión y hasta rechazo que esas regulaciones han provocado en sectores importantes de la literatura de ambos países, que manifiestamente entienden que del reconocimiento de un derecho de la persona jurídica a la no auto-incriminación se sigue sin más que su representante (y en algunos casos un círculo más o menos amplio de otras personas vinculadas al ente) deba ser tratado de un modo equivalente al que corresponde al imputado.

En el caso de España, la cuestión está regulada en los arts. 409 bis y 786 bis de la Ley de Enjuiciamiento Criminal (LECr.) ${ }^{87}$. El primero dispone que en la investigación de un hecho en que esté imputada una persona jurídica se le tome declaración al representante especialmente designado, siendo aplicables las reglas sobre la declaración del imputado en lo que no sea incompatible con su especial naturaleza, "incluidos los derechos a guardar silencio, a no declarar contra si misma y a no confesarse culpable", con lo cual parece equiparar al representante con el imputado. El segundo, sin embargo, luego de disponer básicamente lo mismo para el juicio, contiene un inciso final que altera por completo la comprensión del asunto, al disponer que no pueda designarse como representante a estos efectos "a quien haya de declarar en el juicio como testigo"88.

a cualquiera que los tenga en su poder a manifestarlos y entregarlos a requerimiento, con posibilidad de apremio ( $\$ 111$ StPO.), apremio que, sin embargo, no es procedente contra quien es sospechoso de haber cometido el delito ni contra quienes están liberados por ley de prestar declaración ( $\$ 93$ II StPO.), situación esta última en la que se encontraría el sujeto con poder de decisión conforme al $\$ 17$ VbVG. Sobre las consecuencias directas de esta última norma para los fines de este trabajo véase, escuetamente, STEInINGer, Einhard, Verbandsverantwortlichkeitsgesetz. Kommentar (Wien, Linde, 2006), $\$ 17$ nn. 13 ss., 22, 29; y sobre el régimen general de los objetos relevantes en el derecho austriaco: ReBISANT, Günther, Versteckte Antworten zur Sicherstellung von Beweisgegenständen im Ermittlungsverfahren, en LEWISCH, Peter (editor), Wirtschaftsstrafrecht und Organverantwortlichkeit (Wien - Graz, NW Verlag, 2013), pp. 161 ss.

${ }^{87}$ Introducidos mediante la Ley $\mathrm{N}^{\circ} 37 / 2011$, de 10 de octubre, de medidas de agilización procesal.

${ }^{88}$ Fundamentalmente lo mismo prevé el "Anteproyecto de Nueva Ley de Enjuiciamiento Criminal” de 2011 en sus artículos 51 y 52. El "Anteproyecto" contiene un apartado especial para todas las cuestiones referidas a la persona jurídica imputada (sección $4^{\circ}$ del capítulo $1^{\circ}$ del título $2^{\circ}$ del libro I). El artículo 52.2 reza: "En ningún caso la persona jurídica acusada podrá designar para que acuda a la vista en representación de la entidad a quien haya de declarar como testigo o a quien deba tener cualquier otra intervención en la práctica de la prueba". 
De este modo, si bien se consagra el derecho del representante a no ser obligado a declarar en tal calidad, se aclara al mismo tiempo que si posee información relevante es un testigo como cualquier otro y se hace prevalecer esta última condición, prohibiéndose incluso que el testigo actúe como representante. Parte de la literatura española ha tomado nota de esta consecuencia ${ }^{89}$, entendiendo que la disposición cumple la necesaria función de evitar que las personas jurídicas imputadas pudieran "blindarse" frente a la investigación mediante el expediente de designar como representantes a los testigos que más antecedentes pudieran aportar en su contra y de ese modo obtener su silencio ${ }^{90}$, pero al mismo tiempo critica que, por su carácter absoluto, la regla puede comprometer gravemente el derecho de defensa de la persona jurídica, al impedirle ser representada por los que más saben y están en mejor pie para tomar decisiones de defensa ${ }^{91}$. Sobre esta base se ha propuesto ya de lege lata una interpretación del inciso final del artículo 786 bis LECr. como una prohibición de fraude procesal, entendiendo que sólo opera cuando se pretende designar como representante a personas cuya designación en tal calidad no resulta razonable (en atención a su peso en la organización) y constituye un mero intento de bloquear la investigación penal, con la consecuencia de que en los demás casos el representante podrá actuar como tal aunque sea llamado como testigo, a lo que se agrega que tendrá derecho a guardar silencio a pesar de dicho llamamiento ${ }^{92}$. Más aún, incluso se ha pretendido que esto debe regir no

${ }^{89}$ Otra parte, en cambio, se limita a constatar la consagración del derecho a no declarar del representante, sin extraer consecuencias relevantes de la limitación impuesta a su designación. Así, por ejemplo, Bajo Fernández, Miguel - Feijóo, Bernardo - Gómez-Jara, Carlos, cit. (n. 10), pp. 284 s., 287.

${ }^{90}$ Como de algún modo preveía, antes de la ley, la Circular No $1 / 2011$ de la Fiscalía General del Estado, al instruir que "los Sres. Fiscales cuidarán de que no se utilice la designación del legal representante de la persona jurídica como un recurso para atribuir indebidamente un estatus similar al del imputado a aquellas personas que deban tener en el proceso una intervención diferente. El legal representante de la persona jurídica que no haya sido imputado personalmente y actue en el procedimiento penal en nombre de la misma, no tendrá la condición de imputado pero formalmente gozará de las garantías propias del mismo en la medida en que actúe en nombre de la corporación y a los solos fines de garantizar el derecho de defensa de ésta última" (p. 84).

${ }^{91}$ Dopico, Jacobo, Proceso penal contra personas jurídicas: medidas cautelares, representantes y testigos, en La Ley, 7.796 (13 de febrero de 2012), p. 10; GASCON, Fernando, Proceso penal y persona jurídica (Madrid etc., Marcial Pons, 2012), p. 139; Del Moral, Antonio, Aspectos procesales de la responsabilidad penal de las personas jurídicas, en Zugaldía, José Miguel - Marín de Espinosa, Elena (coordinadores), Aspectos prácticos de la responsabilidad criminal de las personas jurídicas, (Cizur Menor, Aranzadi, 2013), pp. 298 s.; Gimeno, cit. (n. 10), pp. 114 s.

${ }^{92}$ Dopico, Jacobo, cit. (n. 91), pp. 10 s.; Del Moral, cit. (n. 91), p. 299. 
sólo para el sujeto que sea designado específicamente para representar a la persona jurídica en el proceso penal, sino que para todos quienes estuvieran en condiciones de hacerlo ${ }^{93}$.

Si semejante solución es compatible con la letra de la ley es una cuestión que deberá resolver la jurisprudencia española. Lo que interesa destacar aquí es el salto lógico en que incurren los críticos de la regulación. Porque es sin duda efectivo que la regla del inciso final del artículo 786 bis LECr. resulta muy problemática desde la perspectiva del derecho de defensa, pues no parece razonable que el simple llamamiento como testigo impida per se y sin lugar a excepciones ejercer como representante, con lo cual se puede desbaratar la organización interna de la persona jurídica y su estrategia de defensa. Pero de eso no se sigue en absoluto que la única solución al problema pase por negarles, también per se y sin lugar a excepciones, el carácter de testigos y las cargas asociadas a quienes, sin ser imputados, poseen información relevante para el proceso por el solo hecho de que son o podrían ser representantes de la persona jurídica imputada. Esto último no se deja justificar con recurso al derecho de defensa, sino sólo invocando el derecho a no auto-incriminarse de la persona jurídica, lo que, sin embargo, sólo puede ser decisivo si, además de reconocerse la pertinencia de ese derecho, se demuestra que el mismo puede verse conculcado haciendo declarar a terceros que declaran co mo tales y no en representación de la persona jurídica, lo que no es de recibo.

El punto de partida de la ley española es coincidente con el que se ha venido sosteniendo aquí: no hay ninguna razón para prescindir a priori del testimonio de quienes se desempeñan en la persona jurídica, ni aun de sus representantes. El único defecto que cabe reprocharle es que lo haya resuelto de un modo excesivo, potencialmente lesivo para el derecho de defensa de la persona jurídica, sin advertir, tal como no advierten sus críticos, que las personas naturales vinculadas a la persona jurídica pueden actuar en diversas calidades, de modo que bastaba para salvaguardar el contenido estricto de un supuesto derecho de la persona jurídica a no autoincriminarse la prohibición de obligar a los representantes a declarar en tal calidad, representando a la persona jurídica, sin necesidad de interferir en las decisiones internas en materia de representación y sin renunciar a la información que pueden aportar como testigos.

En el caso del derecho italia no, el artículo 44.1 b) del Decreto Legislativo $\mathrm{N}^{\circ} 231 / 2001$, sobre responsabilidad de los entes por delito, dispone

${ }^{93}$ Dopico, Jacobo, cit. (n. 91), pp. 10 s.; Del Moral, Antonio, cit. (n. 91), pp. 299 ss.; en términos similares, aunque al parecer sólo de lege ferenda, Gascón, Fernando, cit. (n. 91), pp. 139, 142. 
que, además de la persona natural imputada por el delito que da lugar a la responsabilidad de la persona jurídica, tampoco puede ser testigo, "la persona que representa al ente" de acuerdo con la declaración formal que se debe hacer ante la autoridad para estos efectos ${ }^{94}$, pero agregando que esto rige en cuanto el representante "revestía tales funciones también al momento de la comisión del delito". De la regulación se desprende con toda claridad que para el legislador italiano las calidades de representante de la persona jurídica y de testigo potencial contra la misma sólo son incompatibles cuando el representante ha tenido esa calidad al tiempo del delito ${ }^{95}$, de modo que en todos los demás casos puede ser llamado a declarar como cualquier otro testigo, sin derecho, en consecuencia, a guardar silencio, al menos no con fundamento en su calidad de representante. Es lo que se desprende también de la "Relación ministerial" (exposición de motivos) del cuerpo normativo, cuando aclara que la equiparación general con el régimen procesal del imputado prevista en el artículo 35 rige para la persona jurídica misma y no para su representante, a quien, aunque se le concedan algunos derechos propios del imputado, en algunos casos se le considera también testigo, afirmación ésta hecha con expresa referencia al mencionado artículo 44 ( $\left.\mathrm{N}^{\circ} 15,2\right)$.

Más aún, en lo que parte de la literatura califica como una contradicción interna de la Relación ministerial, en ésta también se lee que, como consecuencia de la plena equiparación de la persona jurídica con el imputado, el representante será sometido a interrogatorio "por cuenta del ente" (entre comillas en el original) con todas las facultades y derechos del imputado, "comprendida la facultad de no responder", contexto en el cual, además, se habla expresamente de equiparación entre representante e imputado ( $\left.\mathrm{N}^{\circ} 18\right)$. Pero más que una contradicción, esto parece confirmar precisamente lo que se ha venido sosteniendo aquí: que fuera de los casos de incompatibilidad del artículo 44, que tienden a protegerlo a él mismo, el representante sólo tiene derecho a guardar silencio cuando declara en calidad de representante, esto es, "por cuenta del ente", único caso en que se vulneraría un supuesto derecho a guardar silencio de la persona jurídica, debiendo declarar como testigo en todos los demás casos.

${ }^{94}$ De acuerdo con el artículo 39 del mismo cuerpo legal, al cual se remite expresamente el artículo 44.

${ }^{95}$ Lo que más que al interés de la persona jurídica parece atender al del representante, pues quien oficiaba de tal al tiempo del delito será por regla general sospechoso de tener responsabilidad personal en el mismo, con lo cual la incompatibilidad funcionaría como formalización del derecho a no auto-incriminarse propio del representante. Así lo ve, por ejemplo, Amodio, Ennio, Prevenzione del rischio penale di impresa e modelli integrati di responsabilità degli enti, en Cassazione Penale (2005), p. 332. 
No ha sido ésta, sin embargo, la lectura de la literatura italiana. Aunque algunos autores reconocen que, además de permitir el aprovechamiento de información relevante, la solución legal previene que se manipule indebidamente la situación probatoria, suprimiendo testigos por la vía de designarlos como representantes ${ }^{96}$, en general la apreciación que se tiene de ella es crítica y un sector incluso se ha resistido a aceptarla, en parte simplemente abominando de la norma ${ }^{97}$, en parte también con argumentos de texto, fundamentalmente sobre la base del ya citado artículo 35 del Decreto Legislativo ${ }^{98}$. El claro tenor literal de la ley ha impedido que estas lecturas se impongan ${ }^{99}$, no obstante lo cual, en la medida en que tampoco la jurisprudencia lo ha resuelto, reina un ambiente de incertidumbre sobre el asunto.

Desde la perspectiva de este trabajo la incertidumbre es injustificada, al menos en lo que concierne al derecho a no auto-incriminarse de la persona jurídica, porque el contenido conceptualmente necesario de tal derecho está a salvo si se entiende (como puede entenderse, porque el artículo 44 no exige lo contrario y se desprende además de la Relación ministerial)

${ }^{96}$ Rigo, Fabrizio, Il giudizio, en AA. VV., La responsabilità amministrativa degli enti (Milano, IPSOA, 2002), p. 367; FIDELBO, Giorgio, La testimonianza: casi di incompatibilità, en LATTANZI, Giorgio (editor), Reati e responsabilità degli enti (2a edición, Milano, Giuffrè, 2010), p. 498; Giglioni, Marco, Disposizioni generale e soggetti, en D’Aviro, Antonio - Di Amato, Astolfo (editores), La responsabilità da reato degli enti (Vol. X de Di Amato, Astolfo [director], Trattato di diritto penale dell impresa (Padova, CEDAM, 2009), p. 285.

${ }^{97}$ Ferrua, Paolo, Il proceso penale contro gli enti: incoerenze e anomalie nelle regole di accertamento, en GARUTI, Giulio (editor), Responsabilità degli enti per illeciti amministrativi dipendenti da reato (Padova, CEDAM, 2002), pp. 237 ss.

${ }^{98}$ Así, por ejemplo, Amodio, Ennio, cit. (n. 95), p. 332, ha sostenido que sin perjuicio del tenor literal del artículo 44 1.b), una vez que la persona jurídica se constituye en el proceso mediante la designación de un representante en los términos del artículo 39, como a ella se le han reconocido todos los derechos del imputado y a la vez sólo puede actuar mediante representante, éste tiene derecho a guardar silencio por ella; en tanto que Ceresa-GASTALDO, Massimo, $I l$ "proceso alle societă" nel D.Lgs. 8 Giugno 2001, N. 231 (Torino, Giappichelli, 2002), pp. 31 ss. sostiene que el artículo 44.1 b) en realidad no se ocupa de la situación del representante actual, cuya exclusión como testigo ya estaría resuelta por el artículo 35, sino que sólo busca aclarar que el que era representante al tiempo del delito sólo está excluido como testigo cuando se mantiene en tal calidad hasta el proceso, argumento que pasa por invertir el orden de las exigencias legales copulativas: no puede ser testigo la persona que ejercía las funciones de representante al tiempo del delito y que ha sido designada como representante conforme al artículo 39.

${ }^{99}$ Así, entre otros, Rigo, Fabrizio, cit. (n. 96), pp. 367 s.; Fidelbo, Giorgio, cit. (n. 96), p. 497. 
que el representante no puede ser obligado a declarar en calidad de tal, "por cuenta del ente".

Lo único problemático en la regulación es el eventual compromiso del derecho de defensa de la persona jurídica si no se respetan ciertos límites en cuanto a las informaciones sobre las cuales un representante "nuevo", no cubierto por el artículo $44.1 \mathrm{~b}$ ), está obligado a declarar como testigo. Porque para preparar la defensa de la persona jurídica, el representante nuevo, que carece de mayor conocimiento sobre los hechos imputados, debería poder imponerse ahora de los mismos, pero con la confianza de que no podrá ser obligado a declarar como testigo al respecto. Tratándose de la defensa de personas naturales el problema en general no se plantea, porque la información la tiene un imputado con derecho a guardar silencio y los únicos sujetos "nuevos" que se integran a la defensa son sus abogados, protegidos por el secreto profesional, pero se vuelve crítico tratándose de la defensa de personas jurídicas, que por definición sólo actúan representadas, contexto en el cual no es razonable pretender que la información relevante no pase también por su representante ${ }^{100}$.

Es indispensable resolver este problema, que, si bien se mira, se da incluso si se opta, como en el derecho español ${ }^{101}$, por la prohibición de designar como representante a quien deba declarar como testigo, pues en la medida en que siempre se puede atribuir tal calidad al representante designado desde el momento en que se imponga de los hechos relevantes, en un verdadero círculo vicioso, se trata de un problema que siempre concierne al representante actual. La solución pasa por una adecuada interpretación de lo que puede considerarse información relevante que el testigo está obligado a entregar bajo juramento o promesa de decir verdad, que excluya la información obtenida con ocasión de la defensa de la persona jurídica. En caso de no concitar consenso una interpretación de ese tipo, se impone la necesidad de una restricción legal expresa en ese sentido.

Lo relevante para este trabajo es haber mostrado, a través de dos regulaciones concretas, cómo el reconocimiento de un derecho a la no

${ }^{100}$ Ésta es la preocupación que subyace a la propuesta de DiDDI, Alessandro, Il regime dell incompatibilità a testimoniare nel proceso a carico degli enti, en Diritto penale e proceso, 9 (settembre 2005), pp. 1168 s. [coincidente en el resultado FidelBO, Giorgio, cit. (n. 96), p. 501], de distinguir según si el representante "nuevo" tenía conocimiento del hecho y sus circunstancias al momento de ser designado como representante o si carecía de dicho conocimiento, entendiéndose que en el segundo caso debe extenderse a él la incompatibilidad con la calidad de testigo prevista en el artículo $44,1 \mathrm{~b}$.

${ }^{101}$ Como propone interpretativamente para Italia GIARDA, Angelo, Art. 44, en El mismo y otros (editores), Responsabilità "penale" delle persone giuridiche (Milano, IPSOA, 2007), p. 517. 
auto-incriminación de la persona jurídica no supone necesariamente equiparar representante legal con imputado. $\mathrm{Ni}$ aun las deficiencias de las regulaciones en cuestión autorizan a desconocer que es posible establecer un sistema que no renuncie injustificadamente a información relevante para el esclarecimiento de los hechos y que al mismo tiempo salvaguarde los derechos que se le reconozcan a la persona jurídica.

\section{La Cuestión en Chile bajo la Ley Nº 20.393. CONCLUSIONES}

Como se ha visto (II, 4), el Tribunal Constitucional ha resuelto que la Constitución chilena no reconoce un derecho de las personas jurídicas a la no auto-incriminación, de modo que entre nosotros el asunto es uno de legalidad ordinaria, exclusivamente. La cuestión es, entonces, si la ley consagra o no tal derecho.

A favor de una respuesta afirmativa podría contarse el artículo 21 de la Ley $\mathrm{N}^{\circ}$ 20.393, cuyo inciso primero hace aplicables en general a las personas jurídicas las disposiciones relativas al imputado, acusado o condenado, siempre que "resulten compatibles con la naturaleza especifica de las personas jurídicas", señalando luego en su inciso segundo que esto rige en particular para una serie de disposiciones que consagran garantías y derechos específicos ${ }^{102}$, los que "podrán ser ejercidos por cualquier representante de la persona jurídica”. En la medida en que el derecho a no colaborar con la investigación se encuentra legalmente consagrado como un derecho del imputado ${ }^{103}$, es sin duda plausible sostener que, en virtud del artículo 21, la persona jurídica en cuanto imputado tiene también ese derecho, lo que se vería reforzado por la mención específica del artículo 93 CPP., cuya letra g) consagra precisamente el derecho a guardar silencio, así como por la declaración adicional sobre el ejercicio de estos derechos por "cualquier representante" 104 .

${ }^{102}$ En concreto, los artículos 4, 7, 8, 10, 93, 98, 102, 183, 184, 186, 193, 194 y 257 CPP.

${ }^{103}$ En la letra g) del artículo 93 CPP. en lo que respecta al derecho a guardar silencio y en el artículo 217 inciso $2^{\circ} \mathrm{CPP}$. contrario sensu respecto del deber de entregar objetos.

${ }^{104}$ Desde perspectiva española, así razona tácitamente Neira, Ana María, La persona jurídica como nuevo sujeto pasivo del proceso penal en los ordenamientos chileno y español, en Revista de Derecho (Universidad Católica del Norte, Coquimbo), 21 (2014) 1, pp. 166, 172, 175, 197. Durante la tramitación en el Senado y sobre la base de un texto prácticamente idéntico (aunque antes de que se introdujera el inciso segundo), el Prof. Jorge Bofill planteó su preocupación por la falta de regulación del punto (Historia de la Ley 20.393, preparada por la Biblioteca del Congreso Nacional, 
Pero el argumento, aunque plausible, no es decisivo, porque, como ya se ha dicho [II, 5 a)] y el propio precepto reitera, la pertinencia de una garantía procesal respecto de las personas jurídicas depende ineludiblemente del fundamento y naturaleza de la garantía en cuestión, de modo que, en ausencia de una consagración específica expresa, de la sola afirmación genérica de la aplicabilidad a las mismas de los derechos del imputado no se sigue forzosamente que esto deba regir en particular también para el derecho contra la auto-incriminación ${ }^{105}$. Esto no se ve alterado por el listado del inciso segundo, que sigue siendo una remisión genérica, como se desprende de la circunstancia de que, entre los derechos consagrados en las disposiciones listadas, hay algunos que ostensiblemente sólo son aplicables a personas naturales, como es el caso, por ejemplo, del derecho a no ser sometido a tortura ni a otros tratos crueles, inhumanos o degradantes (letra h] del artículo 93 CPP.).

Siendo ineludible entonces el examen de pertinencia del derecho a no auto-incriminarse respecto de las personas jurídicas, aquí se sostiene su impertinencia, por las razones desarrolladas en II,5b) a d), básicamente, porque no se da en ellas el conflicto en que se funda el derecho.

Ahora bien, si, contra lo que se sostiene aquí, se admitiera que bajo la ley chilena las personas jurídicas gozan de un derecho a no auto-incriminarse, en ausencia de normas adicionales que inequívocamente le concedan al representante legal o a otras personas naturales más facultades que las que exige el contenido conceptual necesario de tal derecho, debería admitirse que el representante legal sólo tiene derecho a no ser obligado a declarar o a colaborar de otro modo con la investigación o juicio "en cuanto representante", esto es, actuando en nombre y representación de la persona jurídica (III,1). En lo demás, debería estar sometido al régimen de cualquier

pp. 214 s.). En la misma sede, a favor de una extensión de la garantía a las personas jurídicas se mostró el abogado del Ministerio de Justicia Ignacio Castillo: "Lo novedoso de este precepto [el inciso segundo del artículo 21]... es que podría entenderse que también está referido al representante legal de la empresa, lo que es muy importante, por ejemplo, para los efectos del derecho de [no] auto-incriminarse. Explicó que si el representante legal es citado en calidad de testigo, habría que indicarle que tiene derecho a guardar silencio para no imputar a la empresa" (Historia, p. 296, énfasis agregado). En la literatura chilena sólo se conoce hasta ahora la toma de posición, en contra de esa lectura, de HeRnández, Héctor, La introducción de la responsabilidad penal de las personas jurídicas en Chile, en Política Criminal, 9 (2010), p. 231; y Hernández, Héctor, Desafíos de la ley de responsabilidad penal de las personas juridicas, en Revista de Estudios de la Justicia, 16 (2012), pp. 92 s.

${ }^{105}$ En esto el artículo 21 no avanza más allá de lo que avanzan aquellas disposiciones constitucionales ya citadas que en el extranjero extienden, en principio, los derechos fundamentales también a las personas jurídicas. 
otro tercero que dispone de información relevante para la causa, con la única salvedad (válida aun si no se reconoce el derecho) concerniente a la información que llega a su conocimiento con ocasión, específicamente, de la preparación de la defensa de la persona jurídica (III,2).

\section{BIBLIOGRAFÍA}

Aldunate, Eduardo, Derechos fundamentales (Santiago, LegalPublishing, 2008).

Amodio, Ennio, Prevenzione del rischio penale di impresa e modelli integrati di responsabilità degli enti, en Cassazione Penale (2005).

ARZT, Gunther, Schutz juristischer Personen gegen Selbstbelastung, en JZ. (2003).

ARZT, Gunther, Strafverfahren ohne Menschenrechte gegen juristische Personen, en GRAFL, Christian - Medigovic, Ursula (editores), Festschrift für Manfred Burgstaller (Wien - Graz, NW Verlag, 2004).

Bajo Fernández, Miguel - Fejoóo, Bernardo - Gómez-Jara, Carlos, Tratado de responsabilidad penal de las personas juridicas (Madrid, Civitas, 2012).

BÖSE, Martin, Wirtschaftsaufsicht und Strafverfolgung (Tübingen, Mohr Siebeck, 2005).

Brodowski, Dominik, Minimum Procedural Rights for Corporations in Corporate Criminal Procedure, en Brodowski, Dominik - Espinoza de los Monteros DE la Parra, Manuel - Tiedemann, Klaus - Vogel, Joachim (editores), Regulating Corporate Criminal Liability (Cham etc., Springer, 2014).

Ceresa-Gastaldo, Massimo, Il "proceso alle società" nel D.Lgs. 8 Giugno 2001, N. 231 (Torino, Giappichelli, 2002).

CORDERO, Eduardo, La garantía de no auto-incriminación y el poder punitivo del Estado, en El Mercurio Legal, 6 de septiembre de 2013.

DANNECKER, Gerhard, Beweiserhebung, Verfahrensgarantien und Verteidigungsrechte im europäischen Kartellordnungswidrigkeitenverfahren als Vorbild für ein europäisches Sanktionsverfahren, en ZStW., 111 (1999).

Del Moral, Antonio, Aspectos procesales de la responsabilidad penal de las personas jurídicas, en Zugaldía, José Miguel - Marín de Espinosa, Elena (coordinadores), Aspectos prácticos de la responsabilidad criminal de las personas jurídicas (Cizur Menor, Aranzadi, 2013).

DiDDI, Alessandro, Il regime dell incompatibilità a testimoniare nel proceso a carico degli enti, en Diritto penale e proceso, 9 (settembre 2005).

Dopico, Jacobo, Proceso penal contra personas jurídicas: medidas cautelares, representantes $y$ testigos, en La Ley, 7796 (13 de febrero de 2012).

Dressler, Joshua, Understanding Criminal Procedure (3a edición, Newark - San Francisco, LexisNexis, 2002).

Drope, Katharina, Strafprozessuale Probleme bei der Einführung einer Verbandsstrafe (Berlin, Duncker \& Humblot, 2002).

EngelHarT, Marc, Sanktionierung von Unternehmen und Compliance (Berlin, Duncker \& Humblot, 2010).

FERRUA, Paolo, Il proceso penale contro gli enti: incoerenze e anomalie nelle regole di accertamento, en GARUTI, Giulio (editor), Responsabilità degli enti per illeciti amministrativi dipendenti da reato (Padova, CEDAM, 2002).

Fidelbo, Giorgio, La testimonianza: casi di incompatibilità, en LatTanzI, Giorgio (editor), Reati e responsabilità degli enti (2a edición, Milano, Giuffrè, 2010). 
FrEIER, Friedrich von, Selbstbelastungsfreiheit für Verbandpersonen?, en ZStW., 122 (2010).

Garland, Norman, The Unavailability to Corporations of the Privilege against SelfIncrimination: A Comparative Examination, en N.Y.L. Sch. J. Int'l \& Comp. L., 16 (1996).

GASCÓn, Fernando, Proceso penal y persona jurídica (Madrid, Marcial Pons, 2012).

Giarda, Angelo, Art. 44, en El mISMO et al. (editores), Responsabilità “penale” delle persone giuridiche (Milano, IPSOA, 2007).

Giglioni, Marco, Disposizioni generale e soggetti, en D'Aviro, Antonio - Di Amato, Astolfo (editores), La responsabilità da reato degli enti (Vol. X de Di Amato, Astolfo [director], Trattato di diritto penale dell impresa, Padova, CEDAM, 2009).

Gimeno, Jordi, El proceso penal de las personas jurídicas (Cizur Menor, Aranzadi, 2014).

GoberT, James - PunCH, Maurice, Rethinking Corporate Crime (London, Butterworths, 2003).

Gros Espiell, Héctor, La Convención Americana y la Convención Europea de derechos humanos (Santiago, Editorial Jurídica de Chile, 1991).

Haeusermann, Axel, Der Verband als Straftäter und Strafprozeßsubjekt (Freiburg i.Br., edition iuscrim, 2003)

Helmholz, H.M.: Origins of the Privilege Against Self-Incrimination: The Role of the European Ius Commune, en N.Y.U. L. Rev. 65 (1990).

HeRnández, Héctor, Algunos problemas de la representación de la persona jurídica imputada en el proceso penal, en Doctrina y Jurisprudencia Penal 10 (2012).

Hernández, Héctor, Desafíos de la ley de responsabilidad penal de las personas jurídicas, en Revista de Estudios de la Justicia 16 (2012)

HERNÁNDEZ, Héctor, La introducción de la responsabilidad penal de las personas jurídicas en Chile, en Politica Criminal 9 (2010).

Hill, Jennifer, Corporate Rights and Accountability - The Privilege against SelfIncrimination and the Implications of Environment Protection Authority v. Caltex Refining Co Pty Ltd, en Corp. \& Bus. L.J., 7 (1994).

Hoven, Elisa, Der nordrhein-westfälische Entwurfeines Verbandsstrafgesetzbuchs. Eine kritische Betrachtung von Begründungsmodell und Voraussetzungen der Straftatbestände, en ZIS. (2014).

Joseph, Sarah - Castan, Melissa, The International Covenant on Civil and Political Rights (3a edición, New York, Oxford University Press, 2013).

KöCK, Elisabeth, Nemo-tenetur-Grundsatz für Verbände?, en GRAFL, Christian - MEDIGOVIC, Ursula (editores), Festschrift für Manfred Burgstaller (Wien - Graz, NW Verlag, 2004).

LaFave, Wayne R. - Israel, Jerold H. - King, Nancy J., Criminal Procedure (4a edición, St. Paul, West, 2004).

LangbeIn, John H., The Historical Origins of the Privilege Against Self-Incrimination at Common Law, en Michigan Law Review, 92 (1993-1994).

Levy, Leonard W., Origins of the Fifth Amendment and Its Critics, en Cardozo Law Review, 19 (1997-1998).

Loschin, Lynn, A Comparative Law Approach to Corporations and the Privilege Against Self-Incrimination, en U.C. Davis Law Review, 30 (1996-1997).

Macaluso, Alain, Art. 112, en Kunn, André - Jeanneret, Yvan (editores), Commentaire Romand. Code de procédure pénale suisse (Bâle, Helbing Lichtenhahn, 2011). 
Massing, Gregory, The Fifth Amendment, the Attorney-Client Privilege, and the Prosecution of White-Collar Crime, en Va. Law Review, 75 (1989).

Minoggio, Ingo, Das Schweigerecht der juristischen Person als Nebenbeteiligte im Strafverfahren, en Zeitschrift für Wirtschafts- und Steuerstrafrecht (2003).

Moglen, Eben, Origins of the Constitutional Privilege Against Self-Incrimination, en Michogan Law Review, 92 (1993-1994).

NeIRA, Ana María, La persona jurídica como nuevo sujeto pasivo del proceso penal en los ordenamientos chileno y español, en Revista de Derecho, 21 (Universidad Católica del Norte, Coquimbo, 2014) 1.

PIETH, Mark, Strafverfahren gegen das Unternehmen, en ARNOLD, Jörg y otros (editores), Menschengerechtes Strafrecht. Festschrift für Albin Eser (München, Beck, 2005).

RamsaY, Ross, Corporations and the Privilege against Self-Incrimination, en U.N.S.W. Law Review, 15 (1992).

RANSIEK, Andreas, Unternehmensstrafrecht (Heidelberg, C.F. Müller, 1996).

ReBISANT, Günther, Versteckte Antworten zur Sicherstellung von Beweisgegenständen im Ermittlungsverfahren, en LEWISCH, Peter (editor), Wirtschaftsstrafrecht und Organverantwortlichkeit (Wien - Graz, NW Verlag, 2013).

Rigo, Fabrizio, Il giudizio, en AA. VV., La responsabilità amministrativa degli enti (Milano, IPSOA, 2002).

Rothman, Mitchell L., Life after Doe, en U. Cin. Law Review, 56 (1987-1988).

Saltzburg, Stephen A. - Capra, Daniel J., American Criminal Procedure Investigative (9a edición, St. Paul, West, 2010).

SANGUINÉ, Odone, Derechos fundamentales de las personas jurídicas en el proceso penal, en Ontiveros, Miguel (coordinador), La responsabilidad penal de las personas jurídicas (Valencia, Tirant lo Blanch, 2014).

SCHLÜTER, Jan, Die Strafbarkeit von Unternehmen in einer prozessualen Betrachtung nach dem geltenden Strafprozeßrecht (Frankfurt a. M., Peter Lang, 2000).

SCHULER, Patrick, Zur Diskussion um ein Aussageverweigerungsrecht juristischer Personen, en $J R$. (2003).

SCHÜNEMANN, Bernd, Die aktuelle Forderung eines Verbandsstrafrechts - Ein kriminalpolitischer Zombie, en ZIS. (2014).

STEININGER, Einhard, Verbandsverantwortlichkeitsgesetz. Kommentar (Wien, Linde, 2006).

Stone, Adrienne, Environment Protection Authority v. Caltex Refining Co Pty Ltd. Corporations and the Privilege against Self-Incrimination, en U.N.S. W. Law Review, 17 (1994).

Sweeney, Timothy F., The Fifth Amendment and Collective Entities, en Ohio St. Law Review, 48 (1987).

Theophilopoulos, Constantine, The Corporation and the Privilege against SelfIncrimination, en S. Afr. Mercantile Law Review, 16 (2004).

Trainor, Scott A., A Comparative Analysis of a Corporation's Right Against SelfIncrimination, en Fordham Int'l Law Review, 18 (1994-1995).

Trechsel, Stefan, Human Rights in Criminal Proceedings (New York, Oxford University Press, 2005) . 
van Kempen, Piet Hein, Human Rights and Criminal Justice Applied to Legal Persons, en Electronic Journal of Comparative Law, 14 (2010) 3.

WeIss, Wolfgang, Der Schutz des Rechts auf Aussageverweigerung durch die EMRK, en $N J W$. (1999).

WeIss, Wolfgang, Haben juristische Personen ein Aussageverweigerungsrecht? en JZ. (1998).

WyLIE, Michael, Corporations and the Non-compellability Right in Criminal Proceedings, en Crim. Law Quaterly, 33 (1990-1991). 
